\title{
Effects of functional correction training on injury risk of athletes: A systematic review and meta-analysis
}

\author{
Junxia Chen ${ }^{\text {Corresp., }}{ }^{1}$, Chunhe Zhang ${ }^{1}$, Sheng Chen ${ }^{1}$, Yuhua Zhao ${ }^{1}$ \\ 1 Physical Education College of Hubei University., Hubei University., Wuhan, Hubei Province, China \\ Corresponding Author: Junxia Chen \\ Email address: 775100275@qq.com
}

Background We explored functional correction training using the Functional Movement Screen (FMS ${ }^{\mathrm{TM}}$ ) tool. We also analyzed the effects of training on the injuries of athletes in a systematic review and metaanalysis of non-randomized clinical trials.

Methodology We collected twenty-four articles from PubMed, CENTRAL, Scopus, ProQuest, Web of Science, EBSCOhost, SPORTDiscus, Embase, WanFang, and CNKI that were published between January 1997 to September 2020. Articles were selected based on the following inclusion criteria: randomized and non-randomized controlled trials, studies with functional correction training screened by FMS ${ }^{\mathrm{TM}}$ as the independent variable, and studies with injury risk to the athlete as the dependent variable. Data conditions included the sample size, mean, standard deviation, total FMS ${ }^{\mathrm{TM}}$ scores, number of injuries, and asymmetry movement patterns after interventions in the experimental and control groups. Exclusion criteria included: conference abstracts, cross-sectional studies, articles with retrospective study design.

Results Twelve non-randomized trials were included in the meta-analysis. The injury risk ratio of athletes after functional correction training was $0.39 \mathrm{RR}(95 \%$ confidence interval $[\mathrm{Cl}], 0.24-0.65 ; \mathrm{Z}=-3.57$; $P=0.0003 ; I^{2}=0.0 \%$ ). Functional correction training was found to reduce injury risk by $60 \%$ in the experimental groups when compared with the control groups. Functional correction training improved the total $\mathrm{FMS}^{\mathrm{TM}}$ scores of athletes by $1.72 \mathrm{MD}\left(95 \% \mathrm{Cl}, 1.50-1.93 ; \mathrm{Z}=15.53 ; \mathrm{P}<0.0001 ; \mathrm{I}^{2}=2.6 \%\right)$, indicating an improvement of athletes' functional patterns.

Conclusion Grade B evidence indicates that functional correction training based on FMS ${ }^{\mathrm{TM}}$ may improve the functional patterns of athletes and Grade D evidence indicates that it may reduce the risk of sports injury. However, the true effect is likely to be different from the estimate of the effect. Therefore, further studies are needed to explore the influence of functional correction training on the injury risks of athletes. Protocol registration: CRD42019145287. 
Effects of Functional Correction Training on Injury Risk of Athletes: A Systematic Review and Meta-analysis

1

2 Junxia Chen ${ }^{1}$, Chunhe Zhang ${ }^{2}$, Sheng Chen ${ }^{3}$,Yuhua Zhao ${ }^{4}$

3

$4 \quad$ 1,2,3,4 Physical Education College of Hubei University.

5

6 Corresponding Author:

7 Junxia Chen ${ }^{1}$

$8 \quad$ Physical Education College of Hubei University.

$9 \quad$ Email address: 775100275@qq.com 
20 Abstract

21

22

23

24

\section{Background}

We explored functional correction training using the Functional Movement Screen (FMS ${ }^{\mathrm{TM}}$ ) tool. We also analyzed the effects of training on the injuries of athletes in a systematic review and meta-analysis of non-randomized clinical trials.

\section{Methodology}

We collected twenty-four articles from PubMed, CENTRAL, Scopus, ProQuest, Web of Science, EBSCOhost, SPORTDiscus, Embase, WanFang, and CNKI that were published between January 1997 to September 2020. Articles were selected based on the following inclusion criteria: randomized and non-randomized controlled trials, studies with functional correction training screened by FMS ${ }^{\mathrm{TM}}$ as the independent variable, and studies with injury risk to the athlete as the dependent variable. Data conditions included the sample size, mean, standard deviation, total FMS $^{\mathrm{TM}}$ scores, number of injuries, and asymmetry movement patterns after interventions in the experimental and control groups. Exclusion criteria included: conference abstracts, crosssectional studies, articles with retrospective study design.

\section{Results}

Twelve non-randomized trials were included in the meta-analysis. The injury risk ratio of athletes after functional correction training was $0.39 \mathrm{RR}(95 \%$ confidence interval [CI], 0.24 $\left.0.65 ; \mathrm{Z}=-3.57 ; \mathrm{P}=0.0003 ; \mathrm{I}^{2}=0.0 \%\right)$. Functional correction training was found to reduce injury risk by $60 \%$ in the experimental groups when compared with the control groups. Functional correction training improved the total $\mathrm{FMS}^{\mathrm{TM}}$ scores of athletes by $1.72 \mathrm{MD}(95 \% \mathrm{CI}, 1.50-1.93$; 
$41 \mathrm{Z}=15.53 ; \mathrm{P}<0.0001 ; \mathrm{I}^{2}=2.6 \%$ ), indicating an improvement of athletes' functional patterns.

\section{Conclusion}

43 Grade B evidence indicates that functional correction training based on FMS ${ }^{\mathrm{TM}}$ may improve the

44 functional patterns of athletes and Grade D evidence indicates that it may reduce the risk of

45 sports injury. However, the true effect is likely to be different from the estimate of the effect.

46 Therefore, further studies are needed to explore the influence of functional correction training on

47 the injury risks of athletes.

48 Protocol registration: CRD42019145287. 


\section{Introduction}

63

64

The mechanisms of sports injuries in athletes are complex and multifactorial with many potential risk factors for increasing the risk of injury. FMSTM is used to evaluate the basic sports patterns of athletes and to screen potential risk factors for injury. It comprises seven basic movements: active straight leg raise, shoulder mobility, trunk stability push-up, trunk rotary stability, in-line lunge, hurdle step and deep squat. Each movement is scored on a scale of 1-3 for a total score of 21 points (Cook, Burton \& Hoogenboom, 2006a; Cook, Burton, \& Hoogenboom, 2006b). FMS ${ }^{\text {TM }}$ assists in program design by systematically using corrective exercises to normalize or improve fundamental movement patterns ( Cook, et al., 2011; Cook, et al., 2014a,b). An earlier study reported that injury prevention and performance enhancement programs should consider including FMS ${ }^{\mathrm{TM}}$ or a similar movement screening tool and their associated exercises to normalize dysfunctional movement with the goal of injury reduction and performance improvement (Kiesel,et al., 2011). Therefore, it is important to evaluate the relationship between functional correction training after FMS ${ }^{\mathrm{TM}}$ of athletes and sports injuries.

Functional correction training after FMS ${ }^{\mathrm{TM}}$ has shown inconsistent results when reported in other populations, including a randomized controlled trial of patients undergoing anterior cruciate ligament reconstruction in whom a set of gradually progressive functional corrective training exercises may significantly improve the function and movement of the knee joint (Chao et al., 2018). Several non-randomized controlled trials of firefighters have shown that personalized corrective exercises can improve FMS ${ }^{\text {TM }}$ scores (Basar, 2017; Jafari, Zolaktaf \& Ghasemi, 2019). A series of studies by Frost et al. (2012, 2015a, 2015b, 2015c) reported that the 
83

84

effectiveness of FMS ${ }^{\mathrm{TM}}$ training requires the consideration of various factors, such as the number and type of participants, the scoring method (paper or video), the feedback provided during the test, and supervision by a coach. FMS ${ }^{\mathrm{TM}}$ may not be a viable tool to assess movement behaviors regardless of whether it is graded qualitatively using composite or task scores or quantitatively via kinematic analyses (Frost et al. 2017; David J. Cornell, 2016) and the effect of functional correction training on firefighters after FMS ${ }^{\mathrm{TM}}$ was unclear.

Several non-randomized controlled studies of the functional correction training of athletes (Kiesel et al., 2011,2014; Bayati et al., 2019; Campa et al., 2018; Reila et al., 2019; Kovac et al., 2018) have reported that it may improve their $\mathrm{FMS}^{\mathrm{TM}}$ scores as well as reduce asymmetry in functional patterns. Additional studies (Xuhua et al., 2015; Dinc et al., 2017; Hui et al., 2019) have reported that athletes had significantly improved FMSTM scores and reduced sports injuries. The training of athletes' functional correction after FMS ${ }^{\mathrm{TM}}$ may have been effective. However, these findings must be verified since the studies included small sample sizes, some had no control group, and they lacked a strict randomized control design.

The summarized results of systematic reviews and meta-analyses of the total FMS ${ }^{\mathrm{TM}}$ score of a mixed population to predict the sports injury risk are contradictory and they do not support the predictive validity of FMS ${ }^{\mathrm{TM}}$ (Dorrel et al., 2015; Moran et al., 2017). However, other studies have reported that participants with composite scores equal to or less than 14 had a significantly higher likelihood of an injury compared to those with higher scores (Bonazza et al., 2016). Individuals classified as high risk by FMS ${ }^{\mathrm{TM}}$ are $51 \%$ more likely to be injured than those classified as having a low risk (Bunn, Rodrigues \& Bezerra da Silva, 2019). Two studies 
104 105 106 107 108 109

pertaining to FMS ${ }^{\mathrm{TM}}$ and sports injuries of athletes considered the total scores and asymmetry of the FMSTM to be more useful for evaluating the injury risk of older athletes (Moore et al., 2019). Another review reported that the relationship between the $\mathrm{FMS}^{\mathrm{TM}}$ score and injury is unclear as the heterogeneity of the study populations (type of athletes, age, and sport exposure) and the definition of injury used in the studies made it difficult to draw definitive conclusions (Manuel et al., 2019). Therefore, there is no clear conclusion about the relationship between FMS ${ }^{\mathrm{TM}}$ and sports injuries.

Some reviews that analyzed the effects of functional correction training reported that the plan was effective and improved the limitations of exercise patterns (Lindsay et al., 2015, Kraus et al., 2014). There is currently no meta-analysis or systematic review of this topic, and establishing the impact of functional correction training on sports injuries of athletes is a challenging and important task. We sought to explore the impact of functional correction training after FMS ${ }^{\mathrm{TM}}$ screening on the injury risk of athletes and to determine whether functional correction training after FMS ${ }^{\mathrm{TM}}$ screening could increase total $\mathrm{FMS}^{\mathrm{TM}}$ scores and reduce the incidence of asymmetry in movement patterns of athletes. We hypothesize that functional correction training after FMS ${ }^{\mathrm{TM}}$ may reduce the sports injury risk in athletes.

Materials and Methods

\section{Agreement and registration}

The systematic review and meta-analysis were performed in accordance with the preferred reporting items for systematic reviews and meta-analyses. We followed the Cochrane 
125 Collaboration Handbook while conducting our research (DerSimonian \& Kacker, 2007; Moher,

126 Liberati, Tetzlaff, \& Altman, 2009). This systematic review does not include individual patient

127 data; therefore, ethical approval was not required. The research was registered in PROSPERO

128 (Registration no. CRD42019145287).

\section{Inclusion and exclusion criteria}

Participants: Adolescent and adult athletes; males and females.

Interventions: After initial FMS scores were obtained, athletes were prescribed an individualized

FMS-score-based training program designed to correct the identified movement deficits. The training program included self-administered trigger point treatments, self and partner stretching of major muscle groups, and strength and stability exercises. The intervention plans were conventional training and functional correction training.

Comparator: Studies were required to have a comparator group that performed conventional training only.

Outcomes: Data indicators were sample size, mean, standard deviation, total FMS ${ }^{\text {TM }}$ scores, number of athletes with sports injuries, and functional pattern asymmetry after intervention of the experimental and control groups. Types of studies to be included: Randomized and non-randomized controlled trials were included.

143 Exclusion criteria: Conference abstracts, cross-sectional studies, and retrospective studies were 144 excluded. 
Two authors (S Chen) and (Y Zhao) independently searched the literature. Disagreements

147 over the validity of the findings were solved through consensus and by discussion with a

148 reference author (C Zhang). Ten electronic databases including PubMed, CENTRAL, Scopus,

149 ProQuest, Web of Science, EBSCOhost, SPORTDiscus, Embase, Wanfang, and CNKI were

150 searched for full texts published between January 1997 and September 2020. The following

151 search terms and MeSH terms were used: functional movement screen OR fms* OR functional

152 movement screen* AND injury* OR injury prediction OR injury risk OR injury prevention

153 screening OR athletic injuries [MeSH] AND functional training OR functional correction

154 training OR corrective exercise training AND sport* OR athlete*OR player. Articles written in

155 Chinese were limited to full text. The Chinese version of key words "FMS"

156 and athletes" were also used. Additionally, the references of the selected articles were searched

157 manually to obtain other potentially related studies. Table 1 shows the systematic search strategy.

\section{Data extraction and collection procedure}

All duplicates were removed before our two investigators(S Chen, Y Zhao) independently 
166

167

size, age, and sex); functional correction training program; conventional training program; and main results (average values and standard deviations), including total FMS ${ }^{\mathrm{TM}}$ scores, number of athletes with sports injuries, and functional movement asymmetry after intervention in the experimental group and the control group.

We defined musculoskeletal injuries as sports injuries and they were considered the main outcome as to whether our intervention test reduced the risk of sports injuries. Other additional outcomes were total FMSTM score and functional movement asymmetry. Of these, bilateral muscle function asymmetries through $\mathrm{FMS}^{\mathrm{TM}}$ were defined as functional movement asymmetry of the six basic movements: active straight leg raise, shoulder mobility, trunk rotary stability, inline lunge, hurdle step and deep squat.

\section{Quality evaluation}

The risk of bias in non-randomized studies was assessed in a manner similar to that used for randomized trials as recommended by the Cochrane Collaboration Handbook for bias assessment of non-randomized studies (Higgins \&Green, 2011). Two researchers were asked to independently evaluate the quality of articles according to 11 factors of the PEDro quality score scales (PEDro, https://www.pedro.org.au). The Spearman rank correlation coefficient was calculated to determine inter-rater reliability of the two researchers (Spearman's rho $=0.779$ ), and a strong level of agreement was found.

The systematic error of 15 articles was assessed using Cochrane's risk of bias tool (RevMan; Review Manager, 2020). The same researchers independently scored each trial for the risk of 
187

188

189

190

191

192

193

194

195

196

197

198

199

200

201

202

203

204

205

206

207

bias. In the case of disagreement, a third researcher assessed the questionable item, and agreement was sought by consensus. Each study was graded for the following domains: random sequence generation, allocation concealment, blinding of participants and personnel, blinding of outcome assessment, incomplete outcome data, selective reporting, and other bias. Each domain was rated as having a low or high risk of bias. In the case of insufficient reported information or information with a questionable interpretation that was unclear, the risk of bias for this item was rated as unclear.

\section{Effect index and data aggregation method}

Meta-analyses were performed with R3.3.2. The random effects method or the fixed-effects method was used depending on the heterogeneity (DerSimonian \& Kacker, 2007). The risk ratio (RR) was used to combine the athletes' sports injuries and asymmetry of functional patterns after intervention. The mean difference (MD) was used to combine the athletes' total FMS ${ }^{\mathrm{TM}}$ scores. A 95\% confidence interval (CI) was also used. The effect sizes of the results were evaluated as follows: large effect size, $>0.8$; medium effect size, $0.5-0.79$; and small effect size, $0.00-0.49$ (Higgins and Green, 2011). The heterogeneity of results across studies was evaluated using the $\mathrm{I}^{2}$ statistic as follows: may not be important, 0-40\%; moderate heterogeneity, 30-60\%; substantial heterogeneity, 50-90\%; and considerable heterogeneity, 75-100\% (Higgins \& Thompson, 2002).

Additionally, the adopted significance level was $\mathrm{P} \leqslant 0.05$. The publication bias was tested using Egger's linear regression (Sterne, Egger \& Smith, 2001). Finally, a sensitivity analysis was performed by eliminating the research literature item-by-item and calculating the combined 
208

209

210

211

212

213

214

215

216

217

218

219

220

221

222

223

224

225

226

227

228

5

value of the remaining literature to determine if the results changed.

\section{Level of evidence}

The quality of the evidence associated with the meta-analysis results was assessed using the

Grading of Recommendations Assessment, Development and Evaluation approach (GRADE)

(Guyatt et al., 2011a; Guyatt et al., 2011b; Guyatt et al., 2011c; Guyatt, Oxman \& Montori et al.,

2011d; GRADEpro GDT, 2020).

\section{Results}

\section{Study selection}

We excluded 594 of the 696 articles identified in the initial literature search. Further screening was conducted according to the aforementioned inclusion criteria and quality assessments.

Discrepancies were resolved through third-party mediation. Twenty-four articles met the inclusion criteria and included in the systematic review and 12 were selected for this metaanalysis. None of the included studies were a randomized controlled trial. Figure 1 shows the systematic search strategy and selection process.

\section{Study characteristics}

The study included a total of 538 participants; 258 were included in the experimental group and 280 in the control group. Detailed information regarding the training status is shown in Table 2,3 and 4 . The age of the participants ranged from 9.6 to 26.5 years; the average ages of the 
229

230

231

232

233

234

235

236

237

238

239

240

241

242

243

244

experimental group and control group were $18.56 \pm 4.17$ years and $19.04 \pm 4.92$ years, respectively. The shortest experiment time was 6 weeks and the longest was 20 weeks. The average experiment time was $9.33 \pm 4.32$ weeks. The shortest intervention frequency was twice per week, and the maximum was six times per week. The average intervention frequency was $3.42 \pm 1.39$ times per week. Finally, the shortest duration of each session was 15 minutes, the longest was 60 minutes, and the average was $36.36 \pm 16.75$ minutes.

The included studies were published between January 1997 and September 2020. The sports included for research were baseball (Song et al., 2014), table tennis (Kangkang et al., 2016), volleyball (Xuhua et al., 2015), free kicking (Bodden, Needham \& Chockalingam, 2015), basketball (Klusemann et al., 2012; Hui and Baoai, 2019), soccer (Dinc et al., 2017; Campa, Spiga \& Toselli, 2018; Riela \& Bertollo, 2019; Schneider et al., 2019), tennis (Yildiz, Pinar \& Gelen, 2019), netball (Kovac, 2018), and wrestling (Bayati et al., 2019). Three studies were not included in the meta-analysis for the following reasons: one was missing data regarding the total FMS $^{\mathrm{TM}}$ scores and sports injury but included data regarding the strength and flexibility of the athletes (Song et al., 2014), and two studies had single-group sample sizes fewer than 10 people and very low quality assessment scores (the PEDro quality scale score for physical therapy was only 4 points) (Kim et al., 2014; Armstrong et al., 2019). Furthermore, some studies used a single-group pre-test design method to perform functional correction training for athletes and found that that they had a positive impact on the FMS ${ }^{\mathrm{TM}}$ scores, asymmetric events, and sports injuries (Kiesel, et al., 2011; Jim et al.,, 2015; Toma et al.,2017; Ali et al.,2019; Brende et al., 
249 2018; Baron J et al., 2019; Huebner et al.,2019; Bayrakdar et al., 2020). These studies did not

250 meet the inclusion criteria and were excluded from this report.

251 The standard function correction program, first classified according to the screening results,

252 and then from basic flexibility to basic stability, and finally retraining the action mode. This

253 procedure includes self-managed trigger point therapy; self-based and partner-based stretching

254 exercises for the major muscle groups; and strength, stability, and flexibility exercises. it uses

255 elastic bands, medicine balls, and foam rollers. In 12 studies, after FMS ${ }^{\mathrm{TM}}$ screening, the

256 researchers developed a functional correction training program (including personalized

257 correction training) as an intervention. Some of these studies used mixed interventions, including

258 strength, stability, and jumping (including functional training) of the upper and lower limbs with

259 bare hands or instruments and the Wrestling+ warm-up program (similar functional correction

training) (Klusemann et al., 2012; Bayati et al., 2019). One study did not report whether the

intervention plan was supervised by coaches or researchers (Dinc et al., 2017). Two studies

(Dinc et al.,2017 and Bayati et al., 2019) did not provide any FMSTM assessor qualification

information or reliability tests. All experimental groups performed functional correction and

conventional training or warm-up activities, and the control groups performed either

conventional training or warm-up activities. Two non-randomized trials (Xuhua et al., 2015; Hui

et al., 2019) used scoring thresholds to divide the subjects into a high-risk group (total FMSTM

267 score $\leqslant 14$ ) and low-risk group (total FMS ${ }^{\text {TM }}$ score $\geqslant 14$ ) prior to the test and interventions

268 (Kiesel, Plisky \& Voight, 2007). Our report includes four trials.

269 The numbers of athletes in the experimental and control groups with sports injuries and pattern 
270

271

272

273

274

275

276

277

278

279

280

281

282

283

284

285

286

287

288

289

290

asymmetry during the intervention period were reported after FMS ${ }^{\text {TM }}$ (Xuhua et al., 2015; Hui \&

Baoai, 2019; Dinc et al., 2017; Bodden et al., 2015; Campa et al., 2018; Kangkang et al., 2016).

Dinc et al. (2017) did not report the number of athletes with sports injuries; instead, a selection

of injuries causing an inability to perform athletic activities for more than three weeks was

reported.

\section{Research bias}

The risk of bias was analyzed and a high risk of bias was associated with blinding

procedures (Figures 2and 3). Participant blinding was only described in one study (Campa et al.,

2018). Four studies included random grouping; however, they did not provide any specific

methods. Blinding of the outcome assessors was performed in two studies (Campa et al., 2018;

Riela \& Bertollo, 2019). The outcome evaluators of the other four studies were not blinded, as

repeated measurement reliability, inter-rater reliability, and high-precision professional

electronic instruments were used to record data (Song et al., 2014; Kim et al., 2014; Klusemann

et al., 2012; Yildiz, Pinar \& Gelen, 2019). The selection bias ratings remained unclear due to

either insufficient or unclear information. A low risk of bias attributable to the blinding of

outcome assessment, reporting, and other bias was observed throughout the studies.

We used the PEDro physical therapy quality scale to evaluate article quality and the primary

difference between randomized and non-randomized trials (Table 5). Some studies included

athletes who were randomly divided into groups in a blinded manner (Bobben et al., 2015;

Kovac et al., 2018; Campa et al., 2018; Riela \& Bertollo, 2019). Some studies did not conduct

Peer) reviewing PDF | (2020:10:53313:2:1:NEW 17 Feb 2021) 
291

292

293

294

295

296

297

298

299

300

301

302

303

304

305

306

307

308

309

310

311

random grouping of athletes, therefore, there was no score for this item. In some studies, the

coaches, raters, and participants were not blinded, therefore, scores were not obtained for

questions related to those items. Among the 15 studies, the average score was 5.5 with an overall quality of the literature of average.

\section{Result integration}

We verified the effects of functional correction training on sports injuries of athletes based on the sports injury RR, total FMS ${ }^{\mathrm{TM}}$ score, and functional pattern asymmetry. There was no heterogeneity in the hazard ratio of the influence of functional correction training on athletes' sports injuries (RR, 0.39; 95\% CI, 0.24-0.65; $\mathrm{Z}=-3.57 ; \mathrm{P}=0.0003 ; \mathrm{I}^{2}=0.0 \%$ ) (Figure 4); therefore, the fixed-effects model was used to combine the effect sizes. The incidence of sports injuries in the experimental group was lower than that of the control group, and the injury risk in the experimental group decreased by $60 \%$.

The effect sizes were combined to measure the influence of functional correction training on the total FMS ${ }^{\mathrm{TM}}$ scores (MD, 1.72; 95\% CI, 1.50-1.93; Z=15.53; $\mathrm{P}<0.0001 ; \mathrm{I}^{2}=2.6 \%$ ) (Figure 5). As there was low heterogeneity, the fixed-effects model was used to combine the effect sizes. All results had large effect sizes with significant differences as compared with those of the control group and the functional patterns of athletes were optimized according to Cohen's interpretation standard.

The hazard ratio of the influence of functional correction training on the pattern of asymmetry of athletes showed large heterogeneity $(\mathrm{RR}, 0.45 ; 95 \% \mathrm{CI}, 0.13-1.50 ; \mathrm{Z}=-1.3$; 
$312 \mathrm{P}=0.19 ; \mathrm{I}^{2}=65.2 \%$ ) (Figure 6). Therefore, the random effects model was used to combine the

313 effects and no significant difference was observed when compared with the control group. One

314 study considered that the age of the athlete may explain heterogeneity in the prospective

315 prediction of injury risk by FMS $^{\mathrm{TM}}$ (Moore et al., 2019) and reported that asymmetry determined

316 by FMS ${ }^{\mathrm{TM}}$ is more useful for evaluating the injury risk of senior athletes. Another study included

317 soccer players aged 15.89 \pm 0.53 years (Campa et al. 2018), and two studies included adult-free

318 combat athletes (Bodden et al., 2015) and a national table tennis team (Kangkang et al., 2016).

319 The incidence rates of model asymmetry for adults were lower than that of the younger soccer

320 players. Therefore, our research results are in line with their results. However, a subgroup

321 analysis to determine the source of heterogeneity was impossible as only three cases were

322 included in the sample. Additionally, the total FMS ${ }^{\mathrm{TM}}$ score was not necessarily improved, and a

323 score of 21 was not the goal. Instead, the focus was the identification of asymmetries (Cook et al.,

324 2014b). Further studies are needed to explore the influence of functional correction training on

325 the model asymmetry of athletes.

\section{Publication bias and sensitivity analysis}

The publication bias associated with the influence of functional correction training on athletes'

total $\mathrm{FMS}^{\mathrm{TM}}$ scores was not significant (Egger's linear regression, $\mathrm{t}=-0.096 ; \mathrm{df}=11 ; \mathrm{P}=0.92>0.05$ )

(Figure S1). The sensitivity analysis indicated that the hazard ratios for athletic injuries and total

FMS $^{\text {TM }}$ scores after functional correction training were consistent with those without 
333

334

335

336

337

338

339

340

341

342

343

344

345

346

347

348

349

350

351

352

353

analysis of athletes' asymmetry were slightly different than those before stratification and were not sufficiently stable.

\section{Level of evidence}

The included studies were non-randomized controlled trials, and the level of evidence using GRADE instruments was low (Tables 6 and 7). Altogether, these studies provided a very low level of evidence of the injury risk ratio and asymmetry model of the athlete. The other prevalent outcome showed a moderate level of evidence of athletes' total FMS ${ }^{\mathrm{TM}}$ scores.

\section{Discussion}

Our review explored the influence of functional correction training based on FMS ${ }^{\mathrm{TM}}$ on the sports injury risk of athletes. The results showed that the injury risk of the experimental group was reduced by $60 \%$ after functional correction training, the effect on the total scores of FMS ${ }^{\mathrm{TM}}$ was large, and significantly different from that of the control group. Results of the sensitivity analysis were very robust, and the possibility of publication bias influencing the athletes' total

FMS $^{\text {TM }}$ scores was very low.

A previous review had no consistent conclusion regarding the total FMS $^{\mathrm{TM}}$ score and the risk of subsequent injuries for athletes and mixed populations (Dorrel et al., 2015; Moran et al., 2017;

Bonazza et al., 2016; Bunn et al., 2019; Moore et al., 2019). This review summarized the functional correction training after FMS ${ }^{\mathrm{TM}}$ with the RR for athletes' injuries, total $\mathrm{FMS}^{\mathrm{TM}}$ scores, and asymmetry. We provided standardized evidence and clarified that functional correction 
354 training after FMS ${ }^{\mathrm{TM}}$ can effectively enhance the functional patterns of athletes.

355 The positive effects of functional correction training after FMS ${ }^{\mathrm{TM}}$ on sports injuries may be

356 due to several factors. First, using FMS ${ }^{\mathrm{TM}}$, athletes may discover weaknesses and perform

357 corrections by focusing on their trunk pillar strength, joint flexibility, and joint stability to ensure

358

359

360

361

362

363

364

365

366

367

368

369

370

371

372

373

374

effectiveness. Second, intervention training includes myofascial therapy, dynamic stretching, core stability training, resistance strength training, and combined neuromuscular training. This may improve the imbalance of the muscle groups and the energy transmission effect of the body's kinetic chain (Cook et al., 2011; Cook et al., 2014a; Cook et al., 2014b). Third, functional correction training includes core stability exercises. Enhancing core stability through exercise is common to musculoskeletal injury prevention programs. Core stabilization relies on instantaneous integration among passive, active, and neural control subsystems. Neuromuscular control is critical in coordinating this complex system for dynamic stabilization (Huxel Bliven KC et al., 2013). Fourth, these interventions aim to stimulate the activation of the muscles of the natural nucleus to improve the relationship between the main muscular function and the fundamental movement (Cook \& Fields, 1997; Kiesel et al., 2011). Additionally, an 8-week program with the foam roll has been reported as effective in increasing range of motion in the stand and reach test (Junker D et al., 2011). The theory that functional correction training programs should consist of functional movements related with core stability and shoulder and hamstring flexibility improvement is supported by a study that reported improved strength and flexibility in 62 elite male high school baseball players after participating in a correction training program (Song et al., 2014). Therefore, functional correction training may effectively reduce the 
375 risk of sports injury.

376 This was the first study to evaluate the impact of functional correction training after FMS

377 on athletes' sports injury risk by including non-randomized controlled trials. Grade B evidence

378 indicates that functional correction training based on FMSTM could improve athletes' functional

379 patterns and Grade D evidence indicates that functional correction training may reduce the risk

380 of sports injuries in athletes. The evidence found in this review is reliable and significant for

381 evidence-based clinical practice.

382

Strengths and limitations

Our review had some limitations. First, some relevant literature may have been overlooked despite a search of ten online databases. Second, the methodological limitations of this review include the small sample sizes evaluated within the retained studies, no differentiation among sports, allocation concealment, and evaluator blindness, which may have resulted in an overestimation of the effects of the intervention. Third, because the sample sizes used to determine the sports injury risk and model asymmetry were fewer than 10 , the publication bias test was not completed. Fourth, some studies did not define whether the coaches supervised or corrected the training quality or whether joint intervention was used. Fifth, FMS ${ }^{\mathrm{TM}}$ was limited

by its inability to test a single construct from a composite set of scores. The total FMSTM score of 
396 Conclusions

397 Grade B evidence indicates that functional correction training based on FMSTM could improve 398 the functional patterns of athletes, and Grade D evidence indicates that it may reduce the risk of 399 sports injury. The true effect is likely to be different from the estimate of effect. Therefore, 400 further studies are needed to explore the influence of functional correction training on the injury 401 risks of athletes.

402

403

Acknowledgements

404

We would like to thank Professors Li Shuping, Huang Zhijian, and Yu Lianghua for their

guidance and suggestions in the process of writing the paper. We would also like to thank

Editage for their editing work for this article.

407

408

References

409

410

411

412

413

414

415

416

Akan Bayrakdar, Hilal Kılın, Boz. 2020. The effect of functional movement screen and lower extremity training on hamstring/quadriceps ratio in football players. Physical education of students. 2: 80-85. DOI:10.15561/20755279.2020.0202

Armstrong K, McDevitt B, Baumann K, O’Reilly L, Ramos Y, Reyes C. 2019. Movement capability changes in collegiate basketball players following a corrective exercise programme. https://digitalcommons.linfield.edu/cgi/viewcontent.cgi?article=1431\&context=symposium

Baron J, Bieniec A, Swinarew AS, Gabryś T, Stanula A. 2019. Effect of 12-week functional training intervention on the speed of young footballers. International Journal of 
Bayati R, Shamsi Majelan A, Mirzaei B, Barbas I. 2019. The effect of 12 weeks of wrestling+ warm-up program on functional movement screen scores in cadet wrestlers. Annals of Applied Sport Science 7: 39-47. DOI: 10.29252/aassjournal.7.1.39

Bodden JG, Needham RA, Chockalingam N. 2015. The effect of an intervention program on Strength \& Conditioning Research 29:219-225. DOI: 10.1519/JSC.0b013e3182a480bf

Bonazza NA, Smuin D, Onks CA, Silvis ML, Dhawan A. 2017. Reliability, validity, and injury

Basar MJ. 2017. The influence of corrective exercises on functional movement screen and https://ir.library.illinoisstate.edu/etd/652

Campa F, Spiga F, Toselli S. 2019. The effect of a 20-week corrective exercise program on 
438

439

440

441

442

443

444

445

446

447

448

449

450

451

452

453

454

455

456

457

458

training after anterior cruciate ligament reconstruction: a randomized controlled trial. Journal of Sports Rehabilitation 27:541-545. DOI: 10.1123/jsr.2017-0022.

Cook G, Burton L, Hoogenboom B. 2006a. Pre-participation screening: the use of fundamental movements as an assessment of function - part 1. North American Journal of Sports Physical Therapy 1:62-72.

Cook G, Burton L, Hoogenboom B. 2006b. Pre-participation screening: the use of fundamental movements as an assessment of function - part 2. North American Journal of Sports Physical Therapy, 1:132-139.

Cook G, Burton L, Hoogenboom BJ, Voight M. 2014. Functional movement screening: the use of fundamental movements as an assessment of function-part 1. International Journal of Sports Physical Therapy 9:396-409.

Cook G, Burton L, Hoogenboom BJ, Voight M. 2014. Functional movement screening: the use of fundamental movements as an assessment of function-part 2. International Journal of Sports Physical Therapy 9:549-563.

Cook G. Movement: Functional Movement Systems. Screening-Assessment-Corrective Strategies. Bucuresti, Romania: Lotus Publishing; 2011.

Chapman RF, Laymon AS, Arnold T. 2014. Functional movement scores and longitudinal performance outcomes in elite track and field athletes. International Journal of Sports Physiology Performance 9:203-211. DOI: 10.1123/ijspp.2012-0329

DerSimonian R, Kacker R. 2007. Random-effects model for meta-analysis of clinical trials: an update. Contemporary Clinical Trials 28:105-114. DOI: 10.1016/j.cct.2006.04.004 
459

460

461

462

463

464

465

466

467

468

469

470

471

472

473

474

475

476

477

478

479

Dinc E, Kilinc BE, Bulat M, Erten YT, Bayraktar B. 2017. Effects of special exercise programs

on functional movement screen scores and injury prevention in preprofessional young football players. Journal of Exercise Rehabilitation 13:535-540. DOI:

\section{$10.12965 /$ jer. 1735068.534}

Dorrel BS, Long T, Shaffer S, Myer GD. 2015. Evaluation of the functional movement screen as an injury prediction tool among active adult populations: a systematic review and metaanalysis. Sports Health 7:532-537. DOI: 10.1177/1941738115607445

Frost DM, Beach TAC, Callaghan JP, McGill SM. 2012. Using the functional movement screen to evaluate the effectiveness of training. Journal of Strength and Conditioning Research 26:1620e1630. DOI: 10.1519/JSC.0b013e318234ec59

Frost DM, Beach TAC, Callaghan JP, McGill SM. 2015a. Exercise-based performance enhancement and injury prevention for firefighters: Contrasting the fitness- and movementrelated adaptations to two training methodologies. Journal of Strength and Conditioning Research 29:2441e2459. DOI: 10.1519/JSC.0000000000000923

Frost DM, Beach TAC, Callaghan JP, McGill SM. 2015b. FMSTM scores change with performers' knowledge of the grading criteria- are whole-body movement screens capturing “dysfunction”? Journal of Strength and Conditioning Research 29:3037-3044. DOI: 10.1097/JSC.0000000000000211

Frost DM, Beach TAC, Campbell TL, Callaghan JP, McGill SM. 2015c. An appraisal of the Functional Movement Screen grading criteria -Is the composite score sensitive to risky movement behavior? Physical Therapy in Sport 16:324-330. DOI: 0.1016/j.ptsp.2015.02.001. 
480 Frost DM, Beach TA, McGill SM, Callaghan JP. 2015d. A proposed method to detect kinematic

481

482

483

484

485

486

487

488

489

490

491

492

493

494

495

496

497

498

499

500

differences between and within individuals. Journal of Electromyography and Kinesiology

25:479-487. DOI: 10.1016/j.jelekin.2015.02.012

Frost DM, Beach TAC, McGill SM, Callaghan JP. 2015. The predictive value of general movement tasks in assessing occupational task performance. Work 52:11-18. DOI:

10.3233/WOR-141902

Frost DM, Beach TA, Campbell TL, Callaghan JP, McGill SM. 2017. Can the Functional Movement Screen ${ }^{\mathrm{TM}}$ be used to capture changes in spine and knee motion control following

12 weeks of training? Physical Therapy in Sports 23:50-57. DOI: 10.1016/j.ptsp.2016.06.003

Garbenytė-Apolinskienė T, Šiupšinskas L, Salatkaitė S, Gudas R, Radvila R. 2018. The effect of integrated training program on functional movements patterns, dynamic stability, biomechanics, and muscle strength of lower limbs in elite young basketball players. Sport Sciences for Health 14:245-250. DOI: 10.1007/s11332-017-0409-y

Guyatt GH, Oxman AD, Kunz R, Brozek J, Alonso-Coello P, Rind D, Devereaux PJ, Montori VM, Freyschuss B, Vist G, Jaeschke R, Williams Jr JW, Murad MH, Sinclair D, Falck-Ytter Y, Meerpohl J, Whittington C, Thorlund K, Andrews J, Schünemann HJ. 2011. GRADE guidelines 6. Rating the quality of evidence--imprecision. Journal of Clinical Epidemiology 64:1283-1293. DOI: 10.1016/j.jclinepi.2011.01.012

Guyatt GH, Oxman AD, Kunz R, Woodcock J, Brozek J, Helfand M, Alonso-Coello P, Glasziou P, Jaeschke R, Akl EA, Norris S, Vist G, Dahm P, Shukla VK, Higgins J, Falck-Ytter Y, Schünemann HJ; GRADE Working Group. 2011. GRADE guidelines: 7. Rating the quality 
501

502

503

504

505

506

507

508

509

510

511

512

513

514

515

516

517

518

519

520

521

of evidence--inconsistency. Journal of Clinical Epidemiology 64:1294-1302. DOI:

10.1016/j.jclinepi.2011.03.017 Error! Hyperlink reference not valid.

Guyatt GH, Oxman AD, Kunz R, Woodcock J, Brozek J, Helfand M, Alonso-Coello P, Falck-

Ytter Y, Jaeschke R, Vist G, Akl EA, Post PN, Norris S, Meerpohl J, Shukla VK, Nasser M,

Schünemann HJ, GRADE Working Group. 2011. GRADE guidelines: 8. Rating the quality

of evidence--indirectness. Journal of Clinical Epidemiology 64:1303-1310. DOI:

10.1016/j.jclinepi.2011.04.014

Guyatt GH, Oxman AD, Montori V, Vist G, Kunz R, Brozek J, Alonso-Coello P, Djulbegovic B, Atkins D, Falck-Ytter Y, Williams JW Jr, Meerpohl J, Norris SL, Akl EA, Schünemann HJ.

2011. GRADE guidelines: 5. Rating the quality of evidence--publication bias. Journal of

Clinical Epidemiology 64:1277-1282. DOI: 10.1016/j.jclinepi.2011.01.011

GRADEpro GDT. Online computer program. Available at: https://gradepro.org/.2020.8.30.

Higgins JP, Green S. 2011. Cochrane Handbook for Systematic Reviews of Interventions, version

5.1.0. 2011 [updated March 2011]. The Cochrane Collaboration. Available at:

https:/handbook.cochrane.org.

Higgins JP, Thompson SG. 2002. Quantifying heterogeneity in a meta-analysis. Statistics in Medicine 21:1539-1558. DOI: 10.1002/sim.1186

Huebner BJ, Plisky PJ, Kiesel KB, Schwartzkopf-Phifer K. 2019. Can injury risk category be changed in athletes? An analysis of an injury prevention system. International Journal of Sports Physical Therapy 14:127.

Hui L, Baoai W. 2019. Functional movement screen and rehabilitation training of basketb 
523 Huxel Bliven KC, Anderson BE. Core stability training for injury prevention. Sports Health.

5242013 Nov;5(6):514-22. DOI: 10.1177/1941738113481200.

525 Jafari M, Zolaktaf V, Ghasemi G. 2019. Functional movement screen composite scores in

526 firefighters: effects of corrective exercise training. Journal of Sports Rehabilitation 1-5. DOI:

527 10.1123/jsr.2018-0080

528

529

530

531

532

533

534

535

536

537

538

539

540

541

542

Kangkang Z, Zhuhang H. 2016. The application research of the top level table tennis athlete in the functional movement screen test. Theses and Dissertations. Beijing Sport University. http://new.istic.wanfangdata.com.cn

Kiesel K, Plisky PJ, Voight ML. 2007. Can serious injury in professional football be predicted by a preseason functional movement screen? North American Journal of Sports Physical Therapy 2:147-158.

Kiesel K, Plisky P, Butler R. 2011. Functional movement test scores improve following a standardized off-season intervention program in professional football players. Scandinavian Journal of Medicine \& Science in Sports 21:287-292. DOI: 10.1111/j.16000838.2009.01038.x

Kiesel KB, Butler RJ, Plisky PJ. 2014. Prediction of injury by limited and asymmetrical fundamental movement patterns in American football players. Journal of Sports Rehabilitation 23:88-94. DOI: 10.1123/jsr.2012-0130

Kim H, Lee Y, Shin I, Kim K, Moon J. 2014. Effects of 8 weeks' specific physical training on the rotator cuff muscle strength and technique of javelin throwers. Journal of Physical 
Therapy Science 26:1553-1556. DOI: 10.1589/jpts.26.1553

Klusemann MJ, Pyne DB, Fay TS, Drinkwater EJ. 2012. Online video-based resistance training improves the physical capacity of junior basketball athletes. The Journal of Strength \& Conditioning Research 26:2677-2684. DOI: 10.1519/JSC.0b013e318241b021

Kovac D. 2018. The effect of a six-week functional movement intervention on dynamic knee stability and physical performance in female netball players. Theses and Dissertations.. Stellenbosch University https://scholar.sun.ac.za

Kraus K, Schütz E, Taylor WR, Doyscher R. 2014. Efficacy of the functional movement screen: a review. Journal of Strength \& Conditioning Research 28:3571-3584. DOI: 1 0.1519/JSC.0000000000000556

Jin-Wook Lee, Seok-Am Zhang1, Jang-Kyu Lee. 2015. Effects of combined training on the FMS score in woman rugby national players. Journal of the Korean Society of IndustryAcademia Technology 11:7439-7446. DOI: 10.5762/KAIS.2015.16.11.7439

Junker D, Stöggl T. The Training Effects of Foam Rolling on Core Strength Endurance, Balance, Muscle Performance and Range of Motion: A Randomized Controlled Trial. J Sports Sci Med. 2019 Jun 1;18(2):229-238.

Moher D, Liberati A, Tetzlaff J, Altman D. 2009. Preferred reporting items for systematic reviews and Meta-analyses: the PRISMA statement. PLoS Medicine 6:e1000097. DOI: 10.1371/journal.pmed.1000097

Moore E, Chalmers S, Milanese S, Fuller JT. 2019. Factors influencing the relationship between the functional movement screen and injury risk in sporting populations: a systematic review 
564

565

566

567

568

569

570

571

572

573

574

575

576

577

578

579

580

581

582

583

584

and meta-analysis. Sports Medicine 49:1449-1463. DOI: 10.1007/s40279-019-01126-5

Moran RW, Schneiders AG, Mason J, Sullivan SJ. 2017. Do Functional Movement Screen

(FMSTMTM) composite scores predict subsequent injury? A systematic review with metaanalysis. British Journal of Sports Medicine 51:1661-1669. DOI: 10.1136/bjsports-2016-

096938

Minthorn LM, Fayson SD, Stobierski LM, Welch CE, Anderson BE. 2015. The Functional Movement Screen's ability to detect changes in movement patterns after a training intervention. Journal of Sports Rehabilitation 24:322-326. DOI:10.1123/jsr.2013-0146

PEDro. Available at: https://www.pedro.org.au/english/downloads/pedro-scale/

Riela LA, Bertollo M. 2019. The effectiveness of eight weeks of a movement-based program on functional movement patterns in male professional soccer players. Journal of Physical Education and Sport 19:1976-1983. DOI:10.7752/jpes.2019.s5294

Rippetoe M, Kilgore L, Bradford SE. 2013. Practical Programming for Strength Training, 3rd edition. Wichita Falls, TX: Aasgaard Company.

Review Manager. 2020. RevMan computer program, version 5.4. The Cochrane Collaboration. Available at: https://www.cochrane.org/zh-hans/join-cochrane.

Schneider J, Wiegand Y, Braumann KM, Wollesen B. 2019. Functional and motor deficits in youth soccer athletes-an explorative, quasi-experimental study. Deutsche Zeitschrift für Sportmedizin 70:14-20. DOI: 10.5960/dzsm.2018.358

Song HS, Woo SS, So WY, Kim KJ, Lee J, Kim JY. 2014. Effects of 16-week functional movement screen training program on strength and flexibility of elite high school baseball 
Sorenson EA. 2009. Functional movement screen as a predictor of injury in high school basketball athletes. Theses and Dissertations.,University of Oregon.

http://www.pqdtcn.com/thesisDetails/9E31FD6C3931C71F679A0E44658A9A58

Santos Bunn P, Rodrigues AI, da Silva EB. 2019. The association between the functional movement screen outcome and the incidence of musculoskeletal injuries: a systematic review with meta-analysis. Physical Therapy in Sport 35:146-158. DOI: 10.1016/j.ptsp.2018.11.011

Sterne JA, Egger M, Smith GD. 2001. Investigating and dealing with publication and other biases in meta-analysis. BMJ 323:101-105. DOI: 10.1136/bmj.323.7304.101

Tejani AS, Middleton EF, Huang M, Dimeff RJ. 2019. Implementing a standardized interventional exercise regimen to improve functional movements in female collegiate athletes. International Journal of Sports Physical Therapy 14:117.

Trinidad-Fernandez M, Gonzalez-Sanchez M, Cuesta-Vargas AI. 2019. Is a low Functional Movement Screen score $(\leqslant 14 / 21)$ associated with injuries in sport? A systematic review and meta-analysis. BMJ Open Sport \& Exercise Medicine 5:e000501. DOI: 10.1136/bmjsem2018-000501

Tejani AS, Middleton EF, Huang M, Dimeff RJ. 2019. Implementing a standardized interventional exercise regimen to improve functional movements in female collegiate athletes. International Journal of Sports Physical Therapy 14:117-126.

Xuhua Z, Ye T. 2015. The Experimental Study of Intervention on the Prevention and Treatment of Sports Injury and Improvement of Athletic Performance by Functional Movement Screen 
606 (FMS $\left.{ }^{\mathrm{TM}}\right)$ and Rehabilitation Training Volleyball Players. Theses and Dissertations., 607 Shanghai Institute of Physical Education. http://lib.sus.edu.cn/

608 Yildiz S, Pinar S, Gelen, E. 2019. Effects of 8-week functional vs. traditional training on athletic 609 performance and functional movement on prepubertal tennis players. The Journal of Strength 610 \& Conditioning Research 33:651-661. DOI: 10.1519/JSC.0000000000002956 
Figure 1

Flow diagram of the study selection process 


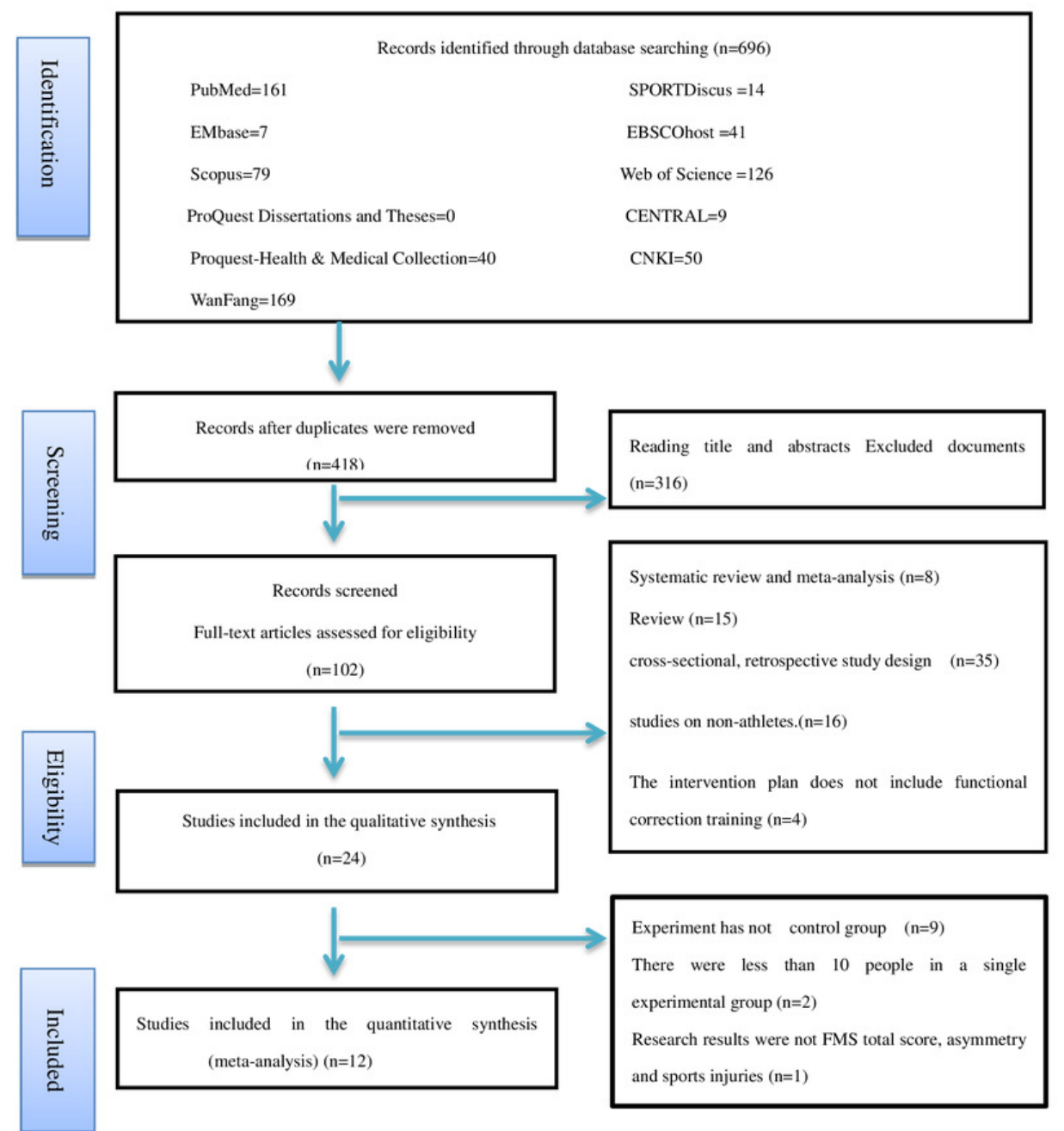


Figure 2

Assessment of bias risk for included studies (risk of bias graph)

Random sequence generation (selection bias)

Allocation concealment (selection bias)

Blinding of participants and personnel (performance bias)

Blinding of outcome assessment (detection bias)

Incomplete outcome data (attrition bias)

Selective reporting (reporting bias)

Other bias
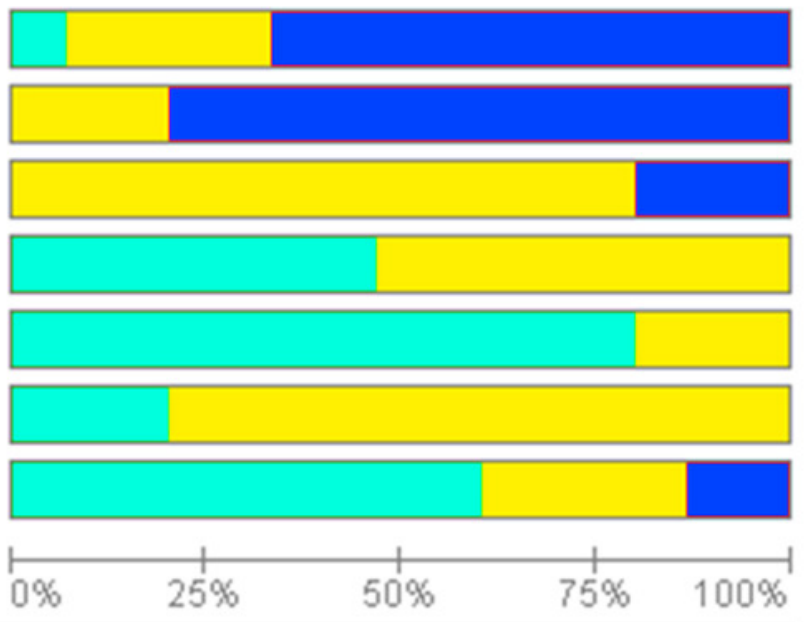
Figure 3

Assessment of bias risk for included studies (risk of bias summary) 


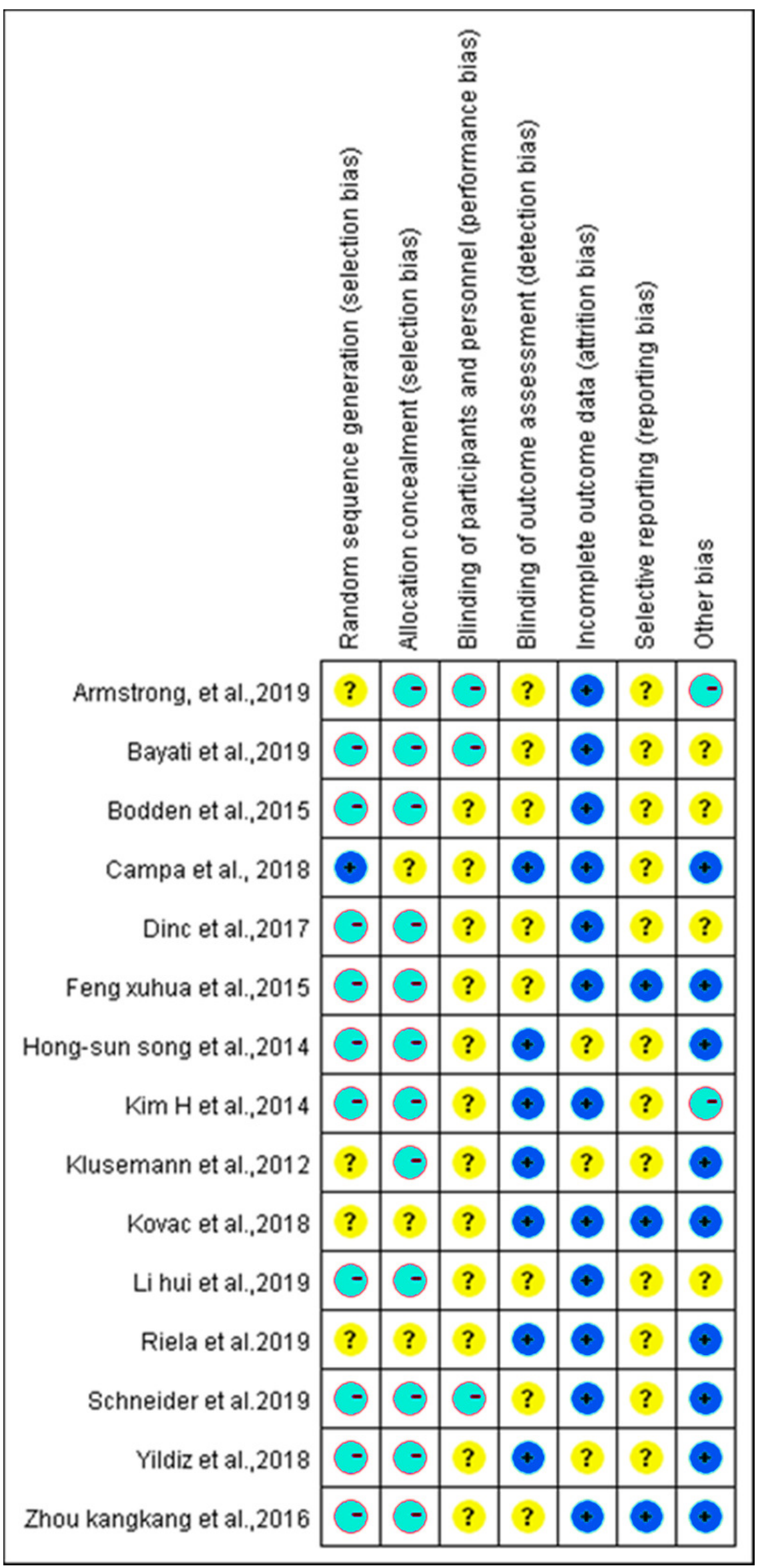


Figure 4

Forest plot of athletes' sports injuries

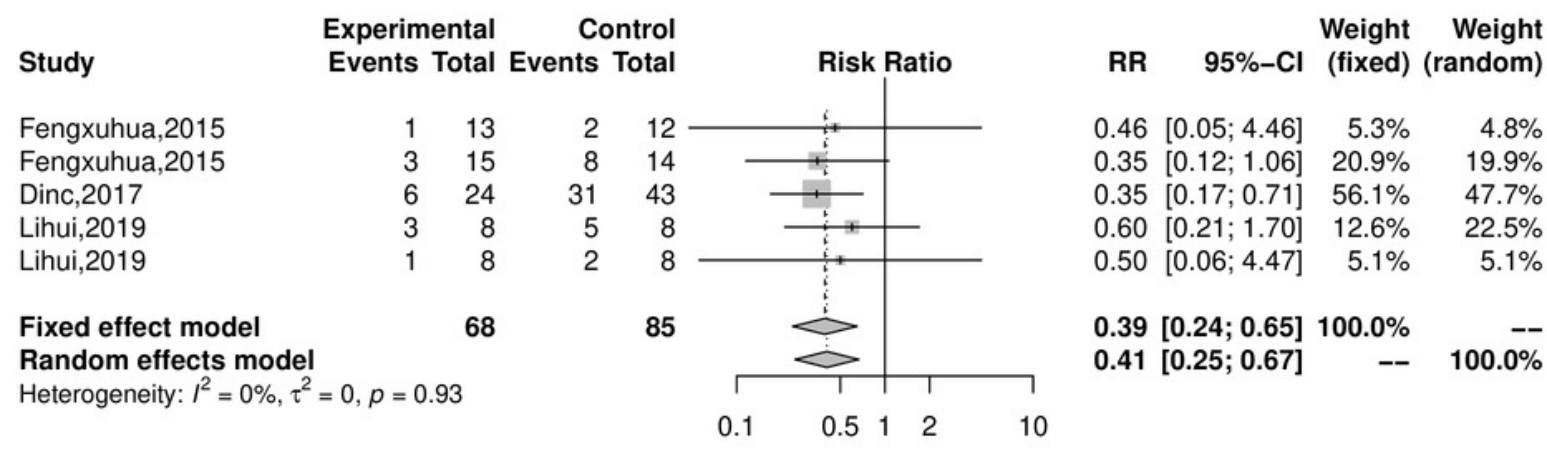


Figure 5

Forest plot of the effect size of the athletes' total FMS ${ }^{\mathrm{TM}}$ score

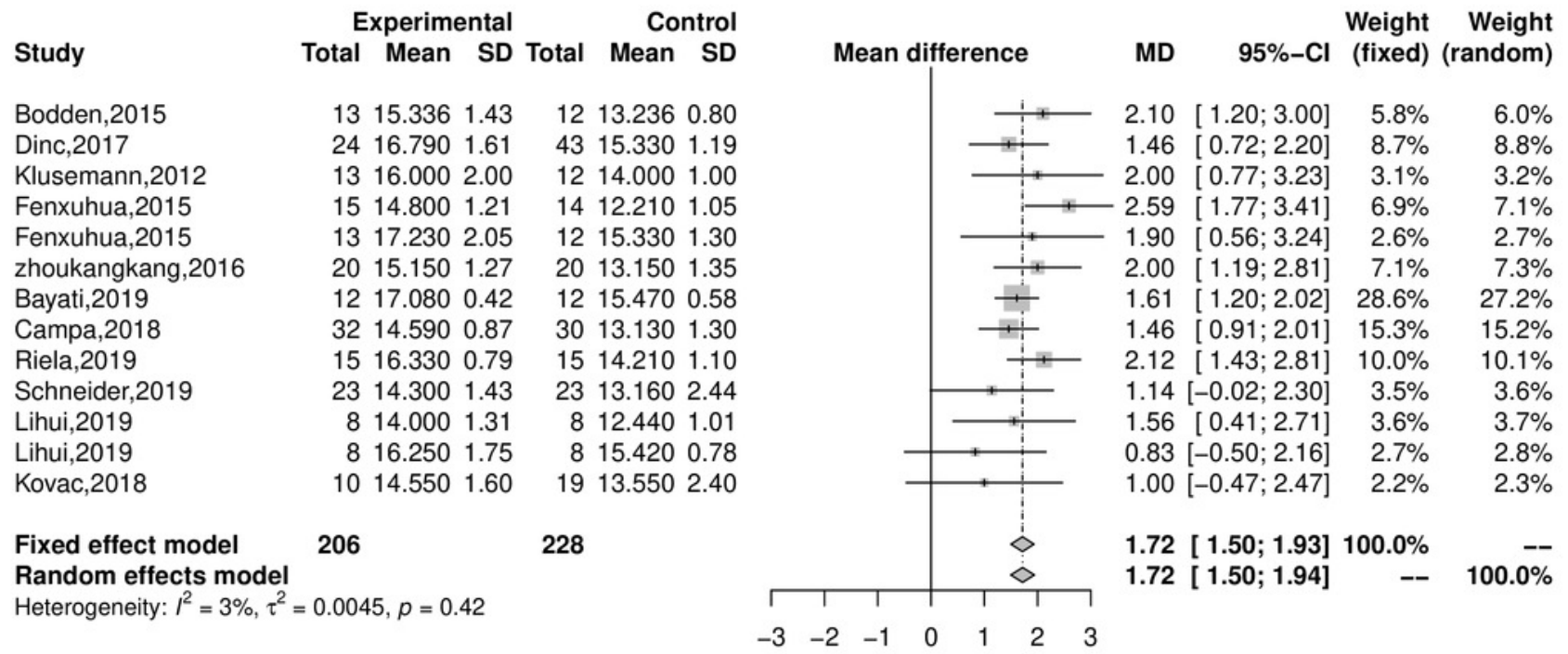


Figure 6

Forest plot of the athletes' asymmetry functional patterns

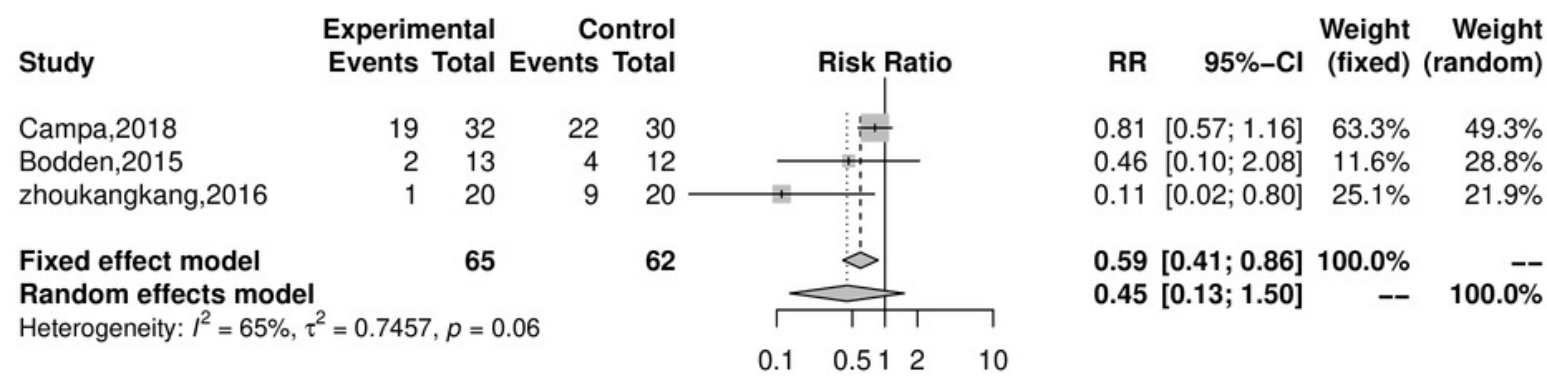


Table $\mathbf{1}$ (on next page)

Search history 


\section{PubMed up to September 2020}

Search: $((((($ functional movement screen) OR (fms*)) OR (functional movement screen*)) AND $(((($ injury*) OR (injury prediction)) OR (injury risk)) OR (injury prevention screening)) OR (Athletic injuries[MeSH]))) AND ((functional training) OR (corrective exercise training) OR(functional correction training)) ) AND ((sport*) OR (athlet*)OR(player)) Filters: Free full text, Full text, from $1997-2020$

\section{Scopus up to September 2020}

TITLE-ABS-KEY ("functional movement screen") OR ("fms* ") OR ("functional movement screen* " ) AND ( "injury*") OR ( "injury prediction" ) OR ("injury risk") OR ("injury prevention screening" ) OR ("Athletic injuries exp" ) AND ( "functional training" ) OR ("corrective exercise training" ) OR("functional correction training") AND ( "sport*" ) OR ( "athlet*" ) OR ("player")

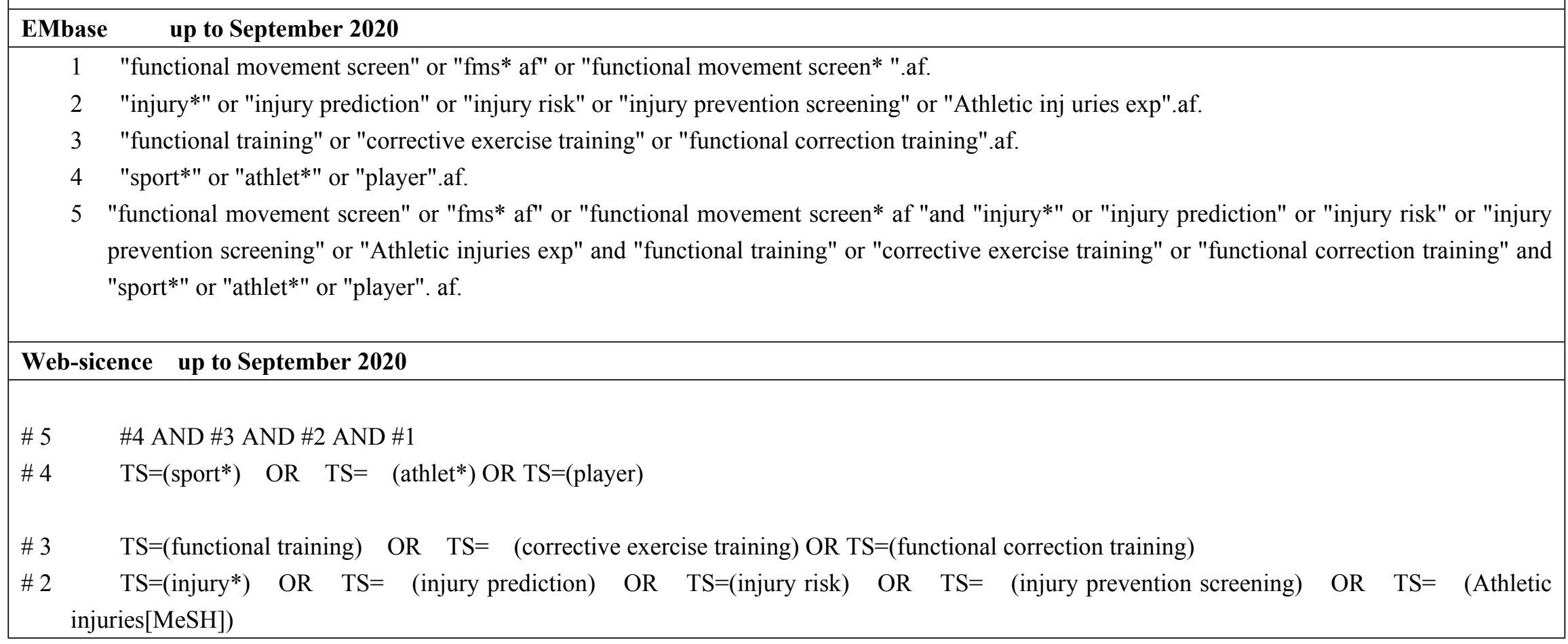




\begin{tabular}{|c|c|}
\hline $\mathrm{TS}=(\mathrm{fu}$ & nctional movement screen) $\mathrm{OR} \quad \mathrm{TS}=\quad(\mathrm{fms} *) \quad \mathrm{OR} \quad \mathrm{TS}=\quad$ (functional movement screen*) \\
\hline EBSOhost & up to September 2020 \\
\hline $\begin{array}{ll}\text { S1 } & ((\text { functional } \\
\text { S2 } & ((((\text { injury*) }) \\
\text { S3 } & (\text { functional t } \\
\text { S4 } & (\text { sport*) OR } \\
\text { S5(((((functional } \\
\quad(\text { injury preven } \\
\text { training)))) Al }\end{array}$ & $\begin{array}{l}\text { movement screen) OR (fms*)) OR (functional movement screen*) } \\
\text { OR (injury prediction)) OR (injury risk)) OR (injury prevention screening)) OR (Athletic injuries[MeSH]) } \\
\text { raining) OR (corrective exercise training) OR (functional corrective training) } \\
(\text { athlet*) OR (player) } \\
\text { movement screen) OR (fms*)) OR (functional movement screen*)) AND ((((injury*) OR (injury prediction)) OR (injury risk)) OR } \\
\text { tion screening)) OR (Athletic injuries[MeSH]))) AND (((functional training) OR (corrective exercise training) OR (functional correction } \\
\mathrm{ND}(((\text { sport*) OR (athlet*) OR (player) }\end{array}$ \\
\hline $\begin{array}{l}\text { CENTRAL } \\
\text { ProQuest- Disser } \\
\text { Proquest-Health }\end{array}$ & $\begin{array}{l}\text { up to September } 2020 \\
\text { tations \& Theses } \\
\text { \& Medical Collection } \\
\end{array}$ \\
\hline $\begin{array}{l}1 \text { "functional mov } \\
2 \text { "injury*" OR "ir } \\
3 \text { "functional train } \\
4 \text { "sport*" OR "at } \\
5 \text { "functional mov } \\
\text { prevention scre } \\
\text { AND "sport*" }\end{array}$ & $\begin{array}{l}\text { sement screen" OR "fms*"OR "functional movement screen" } \\
\text { njury prediction" OR "injury risk" OR "injury prevention screening" OR "Athletic injuries[MeSH]" } \\
\text { ing" OR "corrective exercise training" OR "functional corrective training" } \\
\text { hlet*" OR "player" } \\
\text { rement screen"OR"fms* " OR"functional movement screen* "AND"injury*" OR"injury prediction" OR "injury risk" OR "injury } \\
\text { ening" OR "Athletic injuries[MeSH] " AND "functional training" OR "corrective exercise training" OR "functional correction training" } \\
\text { OR"athlet*" OR "player" }\end{array}$ \\
\hline SPORTDiscus & up to September 2020 \\
\hline $\begin{array}{ll}\text { S1 } & ((\text { functional } \mathrm{m} \\
\text { S2 } & ((((\text { injury*) } \\
\text { S3 } & \text { (functional tr }\end{array}$ & $\begin{array}{l}\text { tovement screen) OR (fms*)) OR (functional movement screen*) } \\
\text { OR (injury prediction)) OR (injury risk)) OR (injury prevention screening)) OR (Athletic injuries[MeSH]) } \\
\text { raining) OR (corrective exercise training) OR (functional corrective training) }\end{array}$ \\
\hline
\end{tabular}


S4 (sport*) OR (athlet*) OR (player)

S5(((((functional movement screen) OR (fms*)) OR (functional movement screen*)) AND (((((injury*) OR (injury prediction)) OR (injury risk)) OR (injury prevention screening)) OR (Athletic injuries[MeSH]))) AND (((functional training) OR (corrective exercise training) OR (functional correction training)))) AND (((sport*) OR (athlet*) OR (player)

CNKI up to September 2020

FMS, functional training, athletes

WANFANG up to September 2020

FMS, functional training, athletes 
Table 2 (on next page)

Base line characteristics of included studies

(A) EG = experimental group, $C G$ = next step. (B) Amstrong's research results only provide histograms and lack data. 


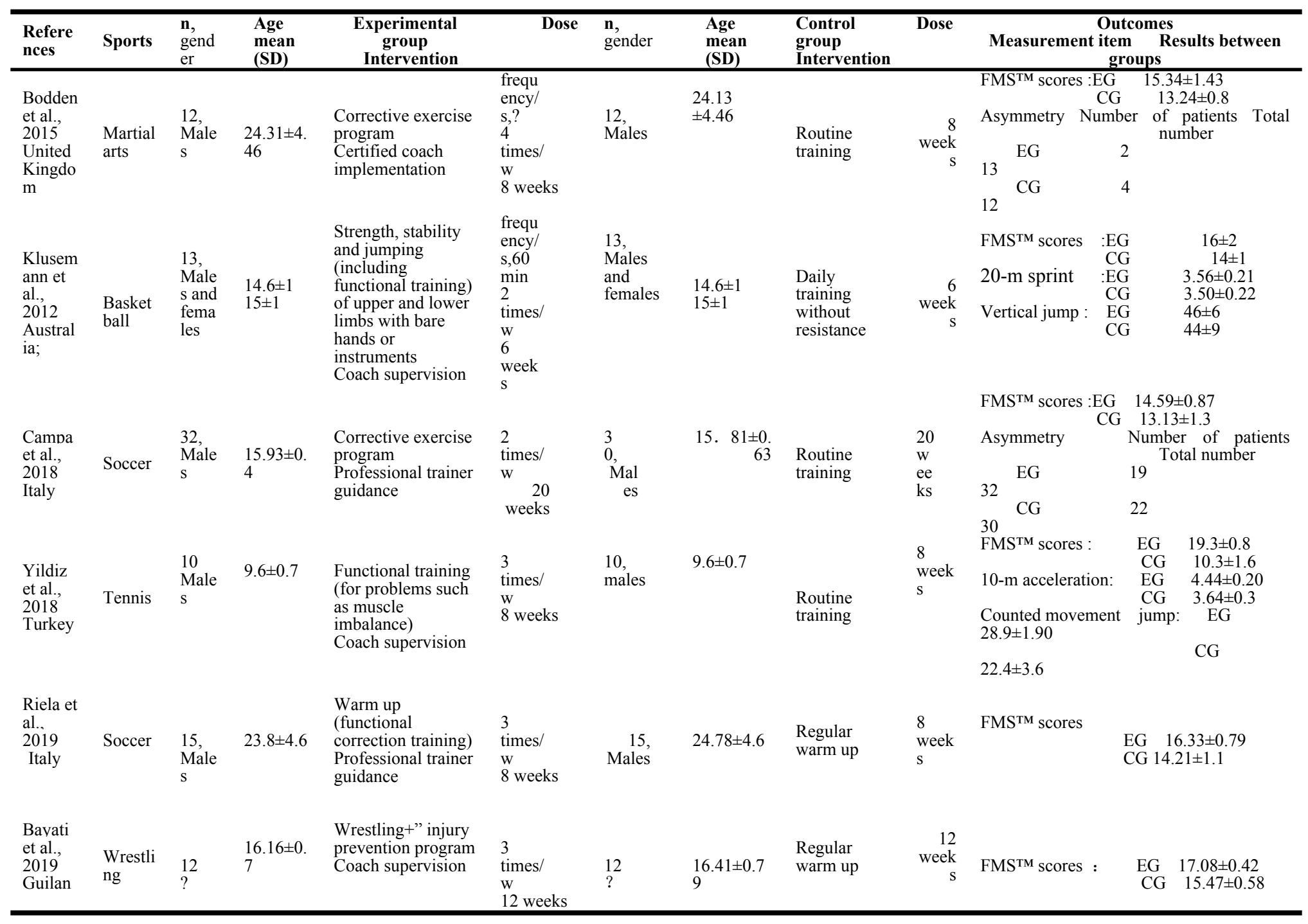


Table 3(on next page)

Base line characteristics of included studies

(A) EG = experimental group, $C G$ = next step. (B) Amstrong's research results only provide histograms and lack data. 


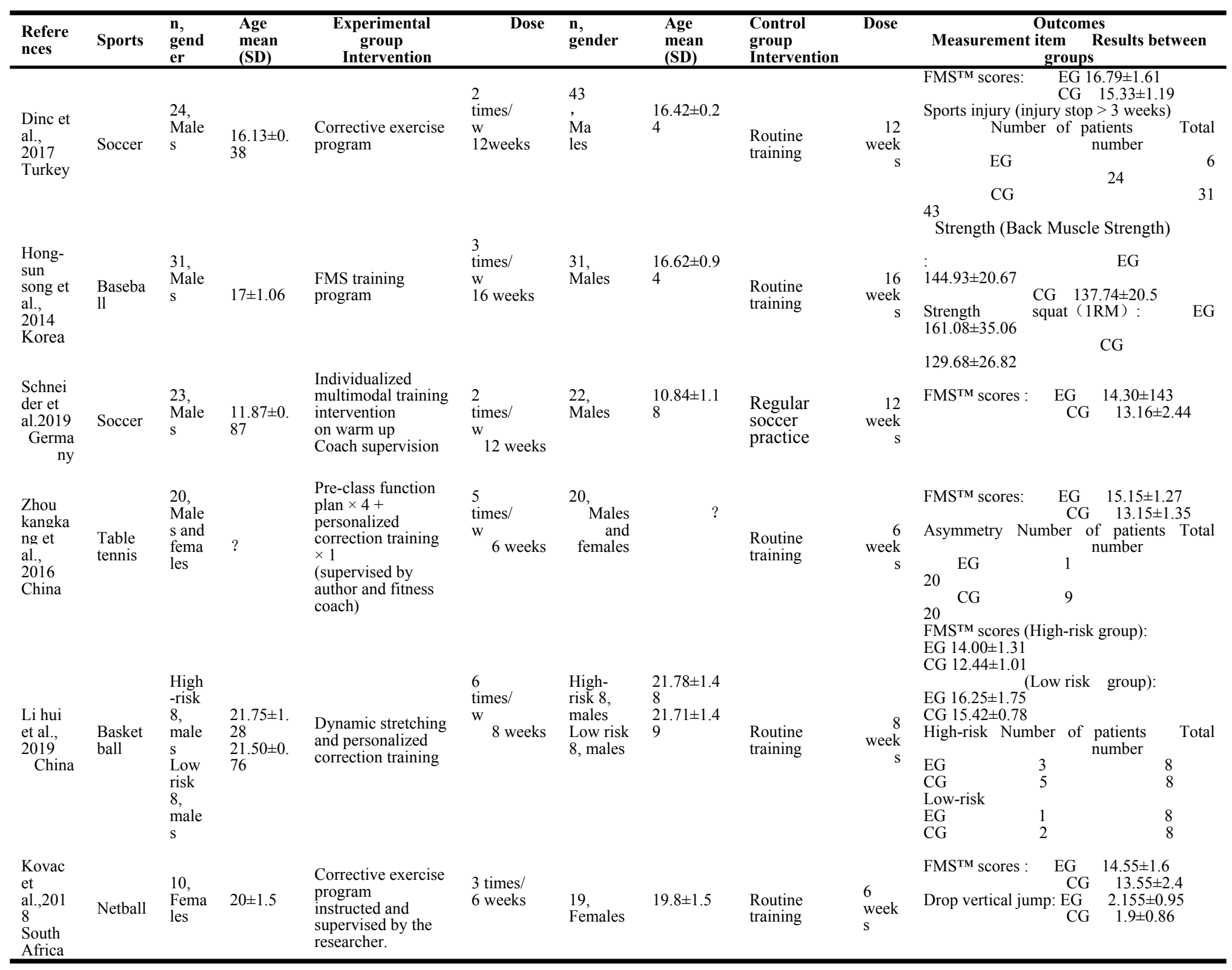


Table 4 (on next page)

Base line characteristics of included studies

(A) EG = experimental group, $C G$ = next step. (B) Amstrong's research results only provide histograms and lack data. 


\begin{tabular}{|c|c|c|c|c|c|c|c|c|c|c|}
\hline $\begin{array}{l}\text { Refere } \\
\text { nces }\end{array}$ & Sports & $\begin{array}{l}\text { n, } \\
\text { gend } \\
\text { er }\end{array}$ & $\begin{array}{l}\text { Age } \\
\text { mean } \\
\text { (SD) }\end{array}$ & $\begin{array}{l}\text { Experimental } \\
\text { group } \\
\text { Intervention }\end{array}$ & Dose & $\begin{array}{l}\text { n, } \\
\text { gender }\end{array}$ & $\begin{array}{l}\text { Age } \\
\text { mean } \\
\text { (SD) }\end{array}$ & $\begin{array}{l}\text { Control } \\
\text { group } \\
\text { Intervention }\end{array}$ & Dose & \begin{tabular}{c}
\multicolumn{2}{c}{ Outcomes } \\
Measurement item Results between \\
groups
\end{tabular} \\
\hline $\begin{array}{l}\text { Armstr } \\
\text { ong, } \\
\text { al.: } \\
2019 \\
\text { USA }\end{array}$ & $\begin{array}{c}\text { Basket } \\
\text { ball }\end{array}$ & $\begin{array}{l}6, \\
\text { Male } \\
\text { s }\end{array}$ & $\begin{array}{c}20.04 \pm 1 \\
4\end{array}$ & $\begin{array}{l}\text { Corrective exercise } \\
\text { program }\end{array}$ & $\begin{array}{l}4 \\
\text { times/ } \\
\text { w } \\
4 \text { weeks }\end{array}$ & 7, Males & $20.04 \pm 1.4$ & $\begin{array}{l}\text { Pre-practice } \\
\text { dynamic } \\
\text { warm-up }\end{array}$ & $\begin{array}{l}4 \\
\text { times } \\
/ \mathrm{w} \\
4 \\
\text { week } \\
\mathrm{s}\end{array}$ & Incomplete data \\
\hline $\begin{array}{l}\text { Feng } \\
\text { xuhua } \\
\text { et al., } \\
2015 \\
\text { C } \\
\text { hi } \\
\text { na }\end{array}$ & $\begin{array}{l}\text { Volley } \\
\text { ball }\end{array}$ & $\begin{array}{l}\text { High } \\
\text {-risk } \\
15, \\
\text { fema } \\
\text { les } \\
\text { Low } \\
\text { risk } \\
13, \\
\text { fema } \\
\text { les }\end{array}$ & $\begin{array}{l}20.92 \pm 3 \\
26 \\
21.47 \pm 3 \\
16\end{array}$ & $\begin{array}{l}\text { Rehabilitation } \\
\text { physical training } \\
\text { (correction } \\
\text { training) }\end{array}$ & $\begin{array}{c}6 \\
\text { times/ } \\
6 \text { weeks }\end{array}$ & $\begin{array}{l}\text { High- } \\
\text { risk 14, } \\
\text { females } \\
\text { Low risk } \\
12, \\
\text { females }\end{array}$ & $\begin{array}{l}21.56 \pm 3.5 \\
8 \\
21.20 \pm 3.3 \\
2\end{array}$ & $\begin{array}{l}\text { Routine } \\
\text { training }\end{array}$ & $\begin{array}{l}6 \\
\text { week } \\
\mathrm{s}\end{array}$ & 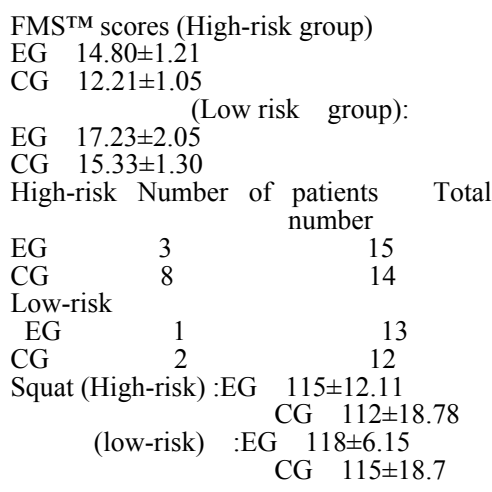 \\
\hline $\begin{array}{l}\text { Kim } H \\
\text { et al., } \\
2014 \\
\text { Korea }\end{array}$ & Javelin & $\begin{array}{l}4, \\
\text { Male } \\
\text { s } \\
2, \\
\text { Fema } \\
\text { les }\end{array}$ & $\begin{array}{l}\text { Males } \\
22 \pm 1.15 \\
\text { Females } \\
22 \pm 1.41\end{array}$ & $\begin{array}{l}\text { Weight, Javelin } \\
\text { specific, core, FMS } \\
\text { training } \\
\text { Performed by } \\
\text { researchers }\end{array}$ & $? / 8$ weeks & $\begin{array}{l}\text { 2, Males } \\
2 \text {, } \\
\text { females }\end{array}$ & $\begin{array}{l}\text { Males } \\
26 \pm 4.24 \\
\text { Females } \\
26.5 \pm 1.41\end{array}$ & $\begin{array}{l}\text { Routine } \\
\text { training }\end{array}$ & $\begin{array}{l}8 \\
\text { week } \\
\mathrm{s}\end{array}$ & $\begin{array}{l}\text { Difference CG-EG } \\
\text { FMS score (points): } \\
\text { CG } 0.30 \pm 1.07 \\
\text { EG-1.03 } \pm 1.37 \\
\text { throwing performances: CG } 9.6 \pm 1.10 \\
\text { EG5.8 } 2.64\end{array}$ \\
\hline
\end{tabular}




\section{Table 5 (on next page)}

Quality assessment results of included studies using the PEDro quality scales

The purpose of the PEDro scale is to help the users of the PEDro database rapidly identify which of the known or suspected randomized clinical trials (i.e., RCTs or CCTs) archived in the database are likely to be internally valid (criteria 2-9), and could have sufficient statistical information to make their results interpretable (criteria 10-11). An additional criterion (criterion 1) that relates to the external validity (or "generalizability" or "applicability" of the trial) has been retained so that the Delphi list is complete, but this criterion will not be used to calculate the PEDro score reported on the PEDro web site. 


\begin{tabular}{|c|c|c|c|c|c|c|c|c|c|c|c|c|c|}
\hline Author & 1 & 2 & 3 & 4 & 5 & 6 & 7 & 8 & 9 & 10 & 11 & $\begin{array}{l}\text { sc } \\
\text { al } \\
\text { e }\end{array}$ & PEDro Scoring item \\
\hline Dinc, 2017 & $\mathrm{Y}$ & $\mathrm{N}$ & $\mathrm{N}$ & $\mathrm{Y}$ & $\mathrm{N}$ & $\mathrm{N}$ & $\mathrm{N}$ & $\mathrm{Y}$ & $\mathrm{Y}$ & $\mathrm{Y}$ & $\mathrm{Y}$ & 5 & 1. eligibility criteria were specified \\
\hline Bodden, 2015 & $\mathrm{Y}$ & $\mathrm{N}$ & $\mathrm{N}$ & $\mathrm{Y}$ & $\mathrm{N}$ & $\mathrm{N}$ & $?$ & $\mathrm{Y}$ & $\mathrm{Y}$ & $\mathrm{Y}$ & $\mathrm{Y}$ & 5 & 2. subjects were randomly allocated to groups \\
\hline Campa ,2018 & $\mathrm{Y}$ & $\mathrm{Y}$ & $\mathrm{N}$ & $\mathrm{Y}$ & $\mathrm{N}$ & $\mathrm{N}$ & Y & $\mathrm{Y}$ & $\mathrm{Y}$ & $\mathrm{Y}$ & Y & 7 & 3. allocation was concealed \\
\hline Kovac,2018 & Y & $\mathrm{Y}$ & $\mathrm{N}$ & $\mathrm{Y}$ & $\mathrm{N}$ & $\mathrm{N}$ & $\mathrm{N}$ & $\mathrm{Y}$ & Y & $\mathrm{Y}$ & Y & 6 & 4. the groups were similar at baseline regarding the most important prognostic indicators \\
\hline Riela,2019 & Y & $\mathrm{Y}$ & $?$ & $\mathrm{Y}$ & $\mathrm{N}$ & $\mathrm{N}$ & $\mathrm{Y}$ & $\mathrm{Y}$ & $\mathrm{Y}$ & $\mathrm{Y}$ & $\mathrm{Y}$ & 7 & 5. there was blinding of all subjects \\
\hline Hong-Sun,2014 & $\mathrm{Y}$ & $\mathrm{N}$ & $\mathrm{N}$ & $\mathrm{Y}$ & $\mathrm{N}$ & $\mathrm{N}$ & $\mathrm{N}$ & $\mathrm{Y}$ & $\mathrm{Y}$ & $\mathrm{Y}$ & $\mathrm{Y}$ & 5 & 6. there was blinding of all therapists who administered the therapy \\
\hline Schneider,2019 & $\mathrm{Y}$ & $\mathrm{N}$ & $\mathrm{N}$ & $\mathrm{Y}$ & $\mathrm{N}$ & $\mathrm{N}$ & $?$ & $\mathrm{Y}$ & $\mathrm{Y}$ & $\mathrm{Y}$ & $\mathrm{Y}$ & 5 & 7. there was blinding of all assessors who measured at least one key outcome \\
\hline $\begin{array}{l}\text { Feng xuhua, } \\
2015\end{array}$ & $\mathrm{Y}$ & $\mathrm{N}$ & $\mathrm{N}$ & $\mathrm{Y}$ & $\mathrm{N}$ & $\mathrm{N}$ & $?$ & $\mathrm{Y}$ & $\mathrm{Y}$ & $\mathrm{Y}$ & $\mathrm{Y}$ & 5 & $\begin{array}{l}\text { 8. measures of at least one key outcome were obtained from more than } 85 \% \text { of the subjects } \\
\text { initially allocated to groups }\end{array}$ \\
\hline $\begin{array}{l}\text { Zhou kang } \\
\text { Kang,2016 }\end{array}$ & $\mathrm{Y}$ & $\mathrm{N}$ & $\mathrm{N}$ & $\mathrm{Y}$ & $\mathrm{N}$ & $\mathrm{N}$ & $\mathrm{N}$ & $\mathrm{Y}$ & $\mathrm{Y}$ & $\mathrm{Y}$ & $\mathrm{Y}$ & 5 & $\begin{array}{l}\text { 9. all subjects for whom outcome measures were available received the treatment or control } \\
\text { condition as allocated or, where this was not the case, data for at least one key outcome was } \\
\text { a analyses by "intention to treat }\end{array}$ \\
\hline $\begin{array}{l}\text { Klusemann, } \\
2012\end{array}$ & Y & $\mathrm{Y}$ & $\mathrm{N}$ & $\mathrm{Y}$ & $\mathrm{N}$ & $\mathrm{N}$ & $?$ & $\mathrm{~N}$ & $\mathrm{Y}$ & $\mathrm{Y}$ & $\mathrm{Y}$ & 5 & $\begin{array}{l}\text { 10. the results of between-group statistical comparisons are reported for at least one key } \\
\text { outcome }\end{array}$ \\
\hline Bayati,2019 & $\mathrm{Y}$ & $\mathrm{N}$ & $\mathrm{N}$ & $\mathrm{Y}$ & $\mathrm{N}$ & $\mathrm{N}$ & $?$ & $\mathrm{Y}$ & $\mathrm{Y}$ & $\mathrm{Y}$ & $\mathrm{Y}$ & 5 & $\begin{array}{l}\text { 11. the study provides both point measures and measures of variability for at least one key } \\
\text { outcome }\end{array}$ \\
\hline Yildiz,2018 & $\mathrm{Y}$ & $\mathrm{N}$ & $?$ & $\mathrm{Y}$ & $\mathrm{N}$ & $\mathrm{N}$ & $?$ & $\mathrm{Y}$ & $\mathrm{Y}$ & $\mathrm{Y}$ & $\mathrm{Y}$ & 5 & \\
\hline Li hui,2019 & $\mathrm{Y}$ & $\mathrm{N}$ & $\mathrm{N}$ & $\mathrm{Y}$ & $\mathrm{N}$ & $\mathrm{N}$ & $\mathrm{N}$ & $\mathrm{Y}$ & $\mathrm{Y}$ & $\mathrm{Y}$ & $\mathrm{Y}$ & 5 & \\
\hline Kim H,2014 & $\mathrm{Y}$ & $\mathrm{N}$ & $\mathrm{N}$ & $?$ & $\mathrm{~N}$ & $\mathrm{~N}$ & $\mathrm{~N}$ & $\mathrm{Y}$ & $\mathrm{Y}$ & $\mathrm{Y}$ & $\mathrm{Y}$ & 4 & \\
\hline Armstrong,2019 & Y & $\mathrm{Y}$ & $\mathrm{N}$ & $?$ & $\mathrm{~N}$ & $\mathrm{~N}$ & $\mathrm{~N}$ & $\mathrm{Y}$ & $\mathrm{Y}$ & $\mathrm{N}$ & $\mathrm{Y}$ & 4 & \\
\hline
\end{tabular}


Table 6(on next page)

Summary of findings 


\section{Effect of Functional Correction Training on Injury Risk of Athletes: A Systematic Review and Meta-analysis}

\begin{tabular}{|c|c|c|c|c|c|c|}
\hline \multicolumn{2}{|c|}{$\begin{array}{l}\text { Patient or population: athletes } \\
\text { Intervention: functional correction training }\end{array}$} & \multicolumn{3}{|c|}{$\begin{array}{l}\text { Setting: sports injury } \\
\text { Comparison: conventional training }\end{array}$} & & \multirow[b]{3}{*}{ Comments } \\
\hline & \multicolumn{2}{|c|}{ Anticipated absolute effects" $(95 \% \mathrm{CI})$} & \multirow[b]{2}{*}{$\begin{array}{l}\text { Relative effect } \\
\qquad(95 \% \mathrm{CI})\end{array}$} & \multirow[b]{2}{*}{$\begin{array}{c}\text { № of participants } \\
\text { (studies) }\end{array}$} & \multirow{2}{*}{$\begin{array}{c}\text { Certainty of the } \\
\text { evidence } \\
\text { (GRADE) }\end{array}$} & \\
\hline Outcomes & $\begin{array}{c}\text { Risk with } \\
\text { conventional } \\
\text { training }\end{array}$ & $\begin{array}{c}\text { Risk with } \\
\text { functional } \\
\text { correction training }\end{array}$ & & & & \\
\hline \multirow{3}{*}{$\begin{array}{l}\text { sports injury risk of } \\
\text { athletes (injury risk) } \\
\text { follow up: mean 6- } \\
12 \text { weeks }\end{array}$} & \multicolumn{2}{|l|}{ Study population } & \multirow{3}{*}{$\begin{array}{c}\text { RR } 0.3932 \\
(0.2386 \text { to } 0.6482)\end{array}$} & \multirow{3}{*}{$\begin{array}{c}153 \\
\text { (5 observational } \\
\text { studies) }\end{array}$} & \multirow{3}{*}{$\begin{array}{c}\oplus \bigcirc \bigcirc \bigcirc \\
\text { VERY } \\
\text { LOW a,b,c,d }\end{array}$} & \multirow{3}{*}{$\begin{array}{l}\text { The injury risk ratio of athletes after functional } \\
\text { correction training was } 0.3932 \mathrm{RR}(95 \% \mathrm{CI} \text {, } \\
\left.0.2386-0.6482 ; \mathrm{Z}=-3.57 ; \mathrm{P}=0.0003 ; \mathrm{I}^{2}=0.0 \%\right) \text {. It } \\
\text { was found that functional correction training } \\
\text { could reduce the injury risk by } 60 \% \text { in the } \\
\text { experimental groups as compared with the } \\
\text { control groups. }\end{array}$} \\
\hline & 565 per 1,000 & $\begin{array}{l}222 \text { per } \mathbf{1 , 0 0 0} \\
(135 \text { to } 366)\end{array}$ & & & & \\
\hline & 0 per 1,000 & $\begin{array}{l}\mathbf{0} \text { per } \mathbf{1 , 0 0 0} \\
(0 \text { to } 0)\end{array}$ & & & & \\
\hline \multirow{4}{*}{$\begin{array}{c}\text { New } \\
\text { outcome (model } \\
\text { asymmetry of } \\
\text { athletes) } \\
\text { assessed with: } \\
\text { Functional } \\
\text { movement screen } \\
\text { follow up: mean 6- } \\
20 \text { weeks }\end{array}$} & \multicolumn{2}{|l|}{ Study population } & \multirow{4}{*}{$\begin{array}{c}\text { RR 0.4460 } \\
\text { (0.1323 to } 1.5033)\end{array}$} & \multirow{4}{*}{$\begin{array}{c}127 \\
(3 \text { observational } \\
\text { studies) }\end{array}$} & \multirow{4}{*}{$\begin{array}{l}\oplus \bigcirc \bigcirc \bigcirc \\
\text { VERY } \\
\text { LOW c,d,e,f }\end{array}$} & \multirow{4}{*}{$\begin{array}{l}\text { The hazard ratio of the influence of functional } \\
\text { correction training on the pattern of asymmetry } \\
\text { of athletes showed large heterogeneity (RR, } \\
0.446 ; 95 \% \text { CI, } 0.1323-1.5033 ; \mathrm{Z}=-1.3 ; \\
\mathrm{P}=0.1928 ; \mathrm{I}^{2}=65.2 \% \text { ). and no significant } \\
\text { difference was observed when compared with the } \\
\text { control group. }\end{array}$} \\
\hline & 565 per 1,000 & $\begin{array}{l}252 \text { per } \mathbf{1 , 0 0 0} \\
\text { (75 to } 849 \text { ) }\end{array}$ & & & & \\
\hline & \multicolumn{2}{|l|}{ Moderate } & & & & \\
\hline & 0 per 1,000 & $\begin{array}{c}\mathbf{0} \text { per } \mathbf{1 , 0 0 0} \\
(0 \text { to } 0)\end{array}$ & & & & \\
\hline Total FMS score of & The mean total & MD 1.7165 MD & - & 434 & $\oplus \oplus \oplus \bigcirc$ & The influence of functional correction training on \\
\hline
\end{tabular}




\begin{tabular}{|c|c|c|c|c|c|}
\hline $\begin{array}{l}\text { athlete } \\
\text { assessed with: }\end{array}$ & $\begin{array}{l}\text { FMS score of } \\
\text { athlete }\end{array}$ & $\begin{array}{c}\text { higher } \\
\text { (1.4999 higher to }\end{array}$ & $\begin{array}{c}\text { (13 observational } \\
\text { studies) }\end{array}$ & MODERATE g,h & $\begin{array}{l}\text { the athletes' total FMS }{ }^{\mathrm{TM}} \text { scores was } 1.7165 \mathrm{MD} \\
\left(95 \% \text { CI, } 1.4999-1.9330 ; \mathrm{Z}=15.53 ; \mathrm{P}<0.0001 ; \mathrm{I}^{2}\right.\end{array}$ \\
\hline $\begin{array}{c}\text { FunctionalMovement } \\
\text { Screen }\end{array}$ & was $13.89 \mathrm{MD}$ & 1.9333 higher) & & & $\begin{array}{l}=2.6 \%) \text {, indicating effective improvement of } \\
\text { athletes' functional patterns. }\end{array}$ \\
\hline \multicolumn{6}{|l|}{ Scale from: 0 to 21} \\
\hline \multicolumn{6}{|l|}{ follow up: range 6} \\
\hline weeks to 20 weeks & & & & & \\
\hline
\end{tabular}

*The risk in the intervention group (and its $95 \%$ confidence interval) is based on the assumed risk in the comparison group and the relative effect of the intervention (and its $95 \% \mathrm{CI})$.

CI: Confidence interval; RR: Risk ratio; MD: Mean difference

\section{GRADE Working Group grades of evidence}

High certainty: We are very confident that the true effect lies close to that of the estimate of the effect

Moderate certainty: We are moderately confident in the effect estimate: The true effect is likely to be close to the estimate of the effect, but there is a possibility that it is substantially different

Low certainty: Our confidence in the effect estimate is limited: The true effect may be substantially different from the estimate of the effect

Very low certainty: We have very little confidence in the effect estimate: The true effect is likely to be substantially different from the estimate of effect

1

\section{Explanations}

3 a. All included studies were not randomized.

4 b. Researchers may have different definition of sports injury/injuries.

5 c. Sample size was small. According to the graph in the GRADE guidelines: 6 . Rating the quality of evidence---imprecision, set RRR=30\%, both injury risk ratio and asymmetry movement patterns of athletes that event rate of the control group was 0.56, at least 500-1,000 samples were required.

d. The publication bias test was not completed because the sample sizes used to determine the sports injury risk and model asymmetry were fewer than 10.

e. Only one study implemented randomization.

f. The hazard ratio of the influence of functional correction training on patterns of athletes' asymmetry had large heterogeneity $(\mathrm{RR}, 0.446 ; 95 \% \mathrm{CI}, 0.1323-1.5033 ; \mathrm{z}=-1.3 ; \mathrm{P}=$ $0.1928 ; \mathrm{I} 2=65.2 \%)$ 
11 g. $66 \%$ of subjects were not randomly allocated to a group.

$12 \mathrm{~h}$. The influence of functional correction training on the athletes' total FMS ${ }^{\mathrm{TM}}$ scores was $1.7165\left(95 \% \mathrm{CI}, 1.4999-1.9330 ; \mathrm{Z}=15.53 ; \mathrm{P}<0.0001 ; \mathrm{I}^{2}=2.6 \%\right)$, Confidence interval 13 exceeded 1. 
Table 7 (on next page)

GRADE evidence profile 
2 Question: Explore functional correction training after the use of Functional Movement Screen (FMS ${ }^{\mathrm{TM}}$ ) and the effects of training on the injuries of athletes.

3 Setting: sports injury Bibliography:

\begin{tabular}{|c|c|c|c|c|c|c|c|c|c|c|c|c|}
\hline \multicolumn{7}{|c|}{ Certainty assessment } & \multicolumn{2}{|c|}{ № of patients } & \multicolumn{2}{|c|}{ Effect } & \multirow[b]{2}{*}{ Certainty } & \multirow[b]{2}{*}{ Importance } \\
\hline $\begin{array}{c}\text { № of } \\
\text { studie } \\
\text { s }\end{array}$ & $\begin{array}{l}\text { Study } \\
\text { design }\end{array}$ & $\begin{array}{c}\text { Risk of } \\
\text { bias }\end{array}$ & $\begin{array}{c}\text { Inconsistenc } \\
\mathbf{y}\end{array}$ & $\begin{array}{c}\text { Indirectnes } \\
\text { s }\end{array}$ & $\begin{array}{c}\text { Imprecisio } \\
\text { n }\end{array}$ & $\begin{array}{c}\text { Other } \\
\text { consideration } \\
\text { s }\end{array}$ & $\begin{array}{l}\text { functiona } \\
\text { I } \\
\text { correctio } \\
\text { n training }\end{array}$ & $\begin{array}{c}\text { conventiona } \\
\text { I training }\end{array}$ & $\begin{array}{c}\text { Relativ } \\
\text { e } \\
(95 \% \\
\text { CI) }\end{array}$ & $\begin{array}{l}\text { Absolute } \\
\text { (95\% CI) }\end{array}$ & & \\
\hline
\end{tabular}

sports injury risk of athletes (follow up: mean 6-12 weeks)

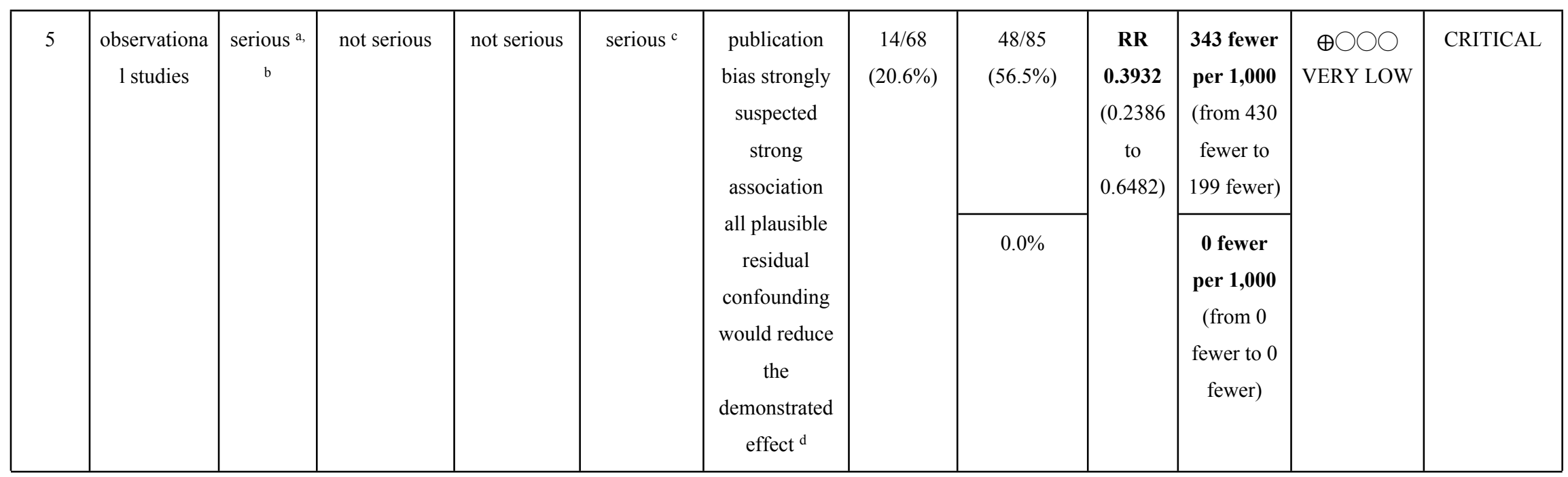

New outcome (follow up: mean 6-20 weeks; assessed with: Functional movement screen)

\begin{tabular}{|c|c|c|c|c|c|c|c|c|c|c|c|c|}
\hline 3 & $\begin{array}{c}\text { observationa } \\
1 \text { studies }\end{array}$ & $\begin{array}{c}\text { very } \\
\text { serious }\end{array}$ & serious ${ }^{f}$ & not serious & serious $^{c}$ & $\begin{array}{c}\text { publication } \\
\text { bias strongly } \\
\text { suspected }\end{array}$ & $\begin{array}{c}22 / 65 \\
(33.8 \%)\end{array}$ & $\begin{array}{c}35 / 62 \\
(56.5 \%)\end{array}$ & $\begin{array}{c}\text { RR } \\
\mathbf{0 . 4 4 6 0} \\
(0.1323\end{array}$ & $\begin{array}{l}313 \text { fewer } \\
\text { per } 1,000 \\
\text { (from } 490\end{array}$ & $\begin{array}{c}\oplus \bigcirc \bigcirc \bigcirc \\
\text { VERY LOW }\end{array}$ & CRITICAL \\
\hline
\end{tabular}




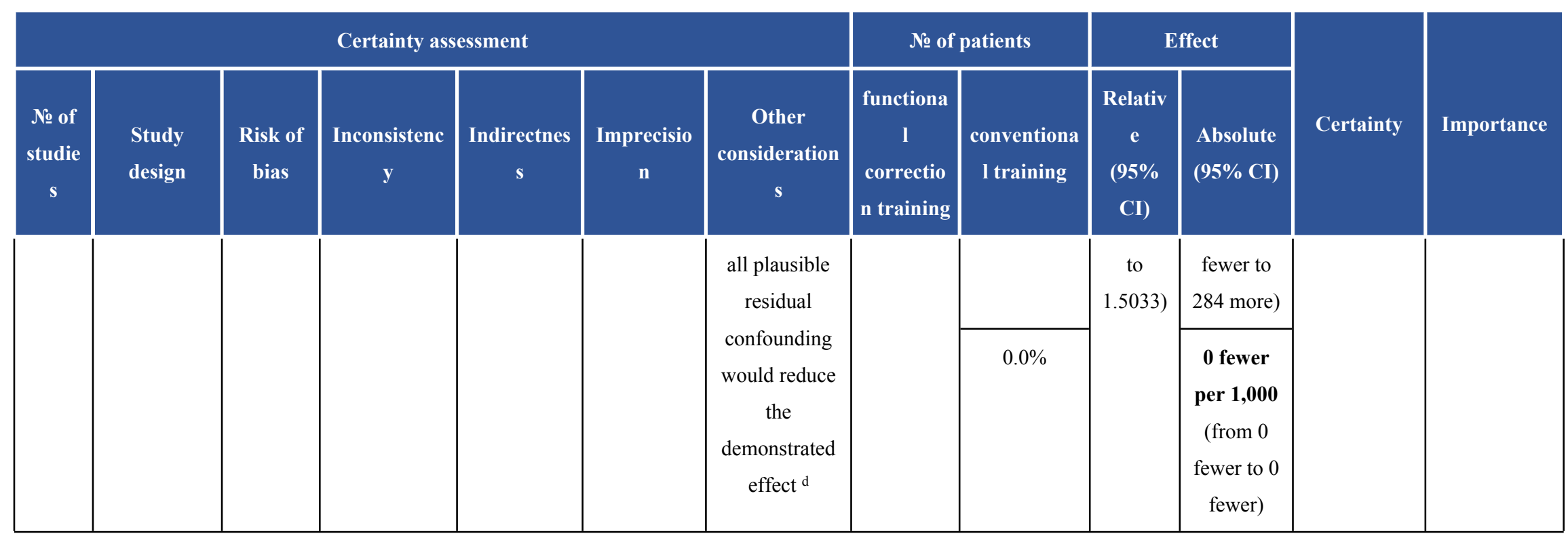

Total FMS score of athlete (follow up: range 6 weeks to 20 weeks; assessed with: Functional Movement Screen; Scale from: 0 to 21)

\begin{tabular}{|c|c|c|c|c|c|c|c|c|c|c|c|c|}
\hline 13 & $\begin{array}{c}\text { observationa } \\
1 \text { studies }\end{array}$ & serious $\mathrm{g}$ & not serious & not serious & serious ${ }^{h}$ & $\begin{array}{c}\text { very strong } \\
\text { association } \\
\text { all plausible } \\
\text { residual } \\
\text { confounding } \\
\text { would reduce } \\
\text { the } \\
\text { demonstrated } \\
\text { effect }\end{array}$ & 206 & 228 & - & $\begin{array}{c}\text { MD } 1.716 \\
5 \text { MD } \\
\text { higher } \\
(1.4999 \\
\text { higher to } \\
1.9333 \\
\text { higher) }\end{array}$ & $\begin{array}{c}\oplus \oplus \oplus \bigcirc \\
\text { MODERAT } \\
\text { E }\end{array}$ & $\begin{array}{c}\text { IMPORTAN } \\
\mathrm{T}\end{array}$ \\
\hline
\end{tabular}

4 CI: Confidence interval; RR: Risk ratio; MD: Mean difference

5 Explanations 
a. All included studies were not randomized.

7 b. Researchers may have different definition of sports injury/injuries.

8 c. Sample size was small. According to the graph in the GRADE guidelines: 6 . Rating the quality of evidence---imprecision, set RRR=30\%, both injury risk ratio and asymmetry

9 movement patterns of athletes that event rate of the control group was 0.56, at least 500-1,000 samples were required.

$10 \mathrm{~d}$. The publication bias test was not completed because the sample sizes used to determine the sports injury risk and model asymmetry were fewer than 10.

11 e. Only one study implemented randomization.

$12 \mathrm{f}$. The hazard ratio of the influence of functional correction training on patterns of athletes' asymmetry had large heterogeneity $(\mathrm{RR}, 0.446 ; 95 \% \mathrm{CI}, 0.1323-1.5033 ; \mathrm{z}=-1.3 ; \mathrm{P}=$ $130.1928 ; \mathrm{I} 2=65.2 \%$

14 g. $66 \%$ of subjects were not randomly allocated to a group.

$15 \mathrm{~h}$. The influence of functional correction training on the athletes' total FMS ${ }^{\mathrm{TM}}$ scores was 1.7165 (95\% CI, 1.4999-1.9330; Z=15.53; P<0.0001; $\left.\mathrm{I}^{2}=2.6 \%\right)$, Confidence interval 16 exceeded 1. 